\title{
Genetic variations of NTCP are associated with susceptibility to HBV infection and related hepatocellular carcinoma
}

\author{
Peng Wang ${ }^{1,2, *}$, Ruidong Mo ${ }^{1,2, *}$, Rongtao Lai ${ }^{1,2, *}$, Yumin Xu ${ }^{1,2}$, Jie Lu ${ }^{2}$, Gangde Zhao ${ }^{1,2}$, \\ Yuhan Liu' ${ }^{1,2}$, Zhujun Cao ${ }^{1,2}$, Xiaolin Wang ${ }^{1,2}$, Ziqiang Li ${ }^{1,2}$, Lanyi Lin ${ }^{1}$, Huijuan Zhou ${ }^{1}$, \\ Wei Cai ${ }^{1}$, Hui Wang ${ }^{1}$, Shisan Bao ${ }^{1,3}$, Xiaogang Xiang ${ }^{1,2}$ and Qing Xie ${ }^{1,2}$ \\ ${ }^{1}$ Department of Infectious Diseases, Ruijin Hospital, Shanghai Jiaotong University School of Medicine, Shanghai, China \\ ${ }^{2}$ Translational Lab of Liver Diseases, Department of Infectious Diseases, Ruijin Hospital, Shanghai Jiaotong University School \\ of Medicine, Shanghai, China \\ ${ }^{3}$ Discipline of Pathology, School of Medical Sciences and Bosch Institute, The University of Sydney, New South Wales 2006, \\ Australia \\ *These authors have contributed equally to this work \\ Correspondence to: Qing Xie, email: xieqingrih@163.com \\ Xiaogang Xiang, email: shine-xxg@163.com \\ Keywords: $\mathrm{Na}^{+}$taurocholate cotransporting polypeptide; association study; HBV; HCC; meta-analysis \\ Received: July 19,2017 Accepted: September 21, 2017 Published: October 31, 2017 \\ Copyright: Wang et al. This is an open-access article distributed under the terms of the Creative Commons Attribution License 3.0 \\ (CC BY 3.0), which permits unrestricted use, distribution, and reproduction in any medium, provided the original author and source \\ are credited.
}

\section{ABSTRACT}

Sodium taurocholate cotransporting polypeptide (NTCP), encoded by gene SLC10A1, is a receptor for hepatitis B virus (HBV). The aim of the current study was to investigate the role of NTCP polymorphisms in HBV susceptibility, cirrhosis and hepatocarcinogenesis. A total 1221 cases [including 866 chronic hepatitis B (CHB), 238 liver cirrhosis (LC), 117 hepatocellular carcinoma (HCC) patients] and 1232 healthy controls (HCs) were recruited, and 6 single nucleotide polymorphisms (SNPs) were genotyped. Meta-analysis was executed among 14591 CHBs and 12396 HCs to determine the association between NTCP polymorphisms and HBV infection, cirrhosis or hepatocarcinogenesis. The frequency of rs2296651-GA was inversely correlated with CHB, LC or HCC patients [adjusted OR(95\%CI $)=0.16(0.11-0.23), p<0.001$; $0.34(0.21-0.55), p=0.001$; or $0.46(0.25-0.83), p=0.008]$, respectively, compared with HCs. Meta-analysis also showed that NTCP rs2296651-GA was inversely associated with $\mathrm{HBV}$ infection $[\mathrm{OR}(95 \% \mathrm{CI})=0.532(0.287-0.986), p=0.028$, codominant] or HBVrelated HCC $[\mathrm{OR}(95 \% \mathrm{CI})=0.701(0.564-0.872), p=0.001$, recessive]. Furthermore, the frequency of rs943277-GA was positively correlated with HBV infection [adjusted OR $(95 \% C I)=2.42(1.05-5.54), p=0.032$, codominant $]$. Our data suggest that NTCP mutants contribute to the susceptibility of HBV infection or HBV-related HCC.

\section{INTRODUCTION}

Chronic hepatitis B (CHB) is still an important challenge to the clinician due to high morbidity $(\sim 350$ million) and mortality ( $\sim 800 \mathrm{k}$ a year) around the world [1]. The prevalence of hepatitis B virus (HBV) infection remains high in China (7.18\%) [2], with $\sim 120$ million chronic HBV carriers [3]. The risk for hepatocellular carcinoma (HCC) in chronic HBV carriers is approximate
40 times higher than that in non-carriers. Furthermore, a large proportion of $\mathrm{CHB}$ patients progress into irreversible liver cirrhosis or $\mathrm{HCC}[4,5]$.

Recently, sodium taurocholate cotransporting polypeptide (NTCP) found on hepatocytes has been considered as a key receptor for HBV infection [6]. NTCP, encoded by the gene SLC10A1, expressed at the basolateral (sinusoidal) membrane of hepatocyte [7], is a determinant for HBV cellular entrance by binding the 
pre-S1 domain of HBV large envelope proteins [6, 8]. NTCP is down-regulated by cyclin D1 in HBV-related HCC, especially in HCC patients with a poor prognosis [9].

The relationship between NTCP polymorphisms and HBV infection or HCC is controversial [10-14]. However, it remains to be explored whether NTCP polymorphisms influence the susceptibility of $\mathrm{HBV}$ infection and the occurrence of liver cirrhosis (LC) or HCC. Therefore, the present study aimed to evaluate the role and clinical relevance of NTCP polymorphisms in HBV susceptibility and HBV-related HCC, especially in the Chinese Han population, using experimental date linked to metaanalysis.

\section{RESULTS}

\section{Demographic and clinical characteristics}

The general demographic characteristics of the study population are shown in Table 1. In total, 2453 participants were identified in the study, including 1221 CHB patients (866 CHB without LC and HCC, 238 CHB with LC, $117 \mathrm{CHB}$ with $\mathrm{HCC}$ ) and $1232 \mathrm{HCs}$ (Table 1). The mean age of $\mathrm{CHB}$ patients was similar to HCs $(46.24 \pm 13.28$ vs $46.51 \pm 13.82$ years, $p=0.419)$. The CHB group had a higher, but not significant, male/ female ratio than $\mathrm{HC}(70.52 \%$ vs $58.36 \%, p=0.077)$. The levels of serum alanine aminotransferase (ALT), aspartate aminotransferase (AST) and alpha-fetoprotein (AFP) in the CHB group were significantly higher than that in $\mathrm{HCs}$ $(p<0.0001)$. In addition, the quantity of HBV DNA in the CHB group (patients without LC or HCC) was higher than that in LC group or with HCC group $(p=0.006)$ (Table 1$)$.

\section{Quality assessment}

In total, 6928 variants of 6 loci were successfully genotyped in the 2453 samples. The rates of successful genotyping (call rate) ranged from $96.5 \%$ to $100 \%$ (Supplementary Table 2). Hardy-Weinberg disequilibrium was assessed, using the HaploView 4.2 test. The genotype distribution of these 6 SNPs was in accord with the HardyWeinberg equilibrium in the HCs (Supplementary Table 2 ). Based on applying these quality control measures, these results were suitable for genetic analysis.

\section{Inverse association between NTCP rs2296651 mutant and HBV susceptibility}

The minor allele frequency (MAF) was compared between CHB patients and HCs. The frequency of the minor A allele at rs2296651 in CHB patients was significantly lower than that of HCs in discovery group $[\mathrm{OR}(95 \% \mathrm{CI})=0.19(0.09-0.38), p<0.001]$ (Table 2). A different frequency distribution of the rs2296651 mutant between $\mathrm{CHB}$ and $\mathrm{HCs}$ was also found in the replication group $\quad[\mathrm{OR}(95 \% \mathrm{CI})=0.20(0.14-0.93), \quad p<0.001] . \quad$ In total, the frequency of A allele at rs2296651 in CHB patients was inversely correlated with $\mathrm{HBV}$ infection $[\mathrm{OR}(95 \% \mathrm{CI})=0.19(0.14-0.26), p<0.001]$ (Table 2).

Subsequently, genetic models (codominant, dominant, recessive and additive) were applied to calculate genotype frequencies. A multivariate logistic regression analysis was performed to identify the variation on rs2296651 independently associated with HBV infection. Age and gender covariates were included in the logistic regressions, which has been previously reported to be significantly associated with HBV infection [15]. In the codominant model, the frequency of GA genotypes in CHB patients accounted for a relatively small proportion of effect (Adjusted $\mathrm{OR}_{\mathrm{I}}=0.17, p<0.001$ and Adjusted $\mathrm{OR}_{\mathrm{II}}=0.16, p<0.001$, adjusted by logistic regression), compared to that of HCs (Table 2). Similarly, the frequency of GA+AA genotypes in the recessive model in $\mathrm{CHB}$ patients was significantly lower than that in $\mathrm{HCs}$ (4\% vs $\left.19.4 \%, \mathrm{AOR}_{\mathrm{I}}=0.17, p<0.001\right)$ in the discovery group. The trend was verified again in the replication group (4.9\% vs 21.9\%, $\left.\mathrm{AOR}_{\mathrm{II}}=0.19, p<0.001\right)$ (Table 2). Moreover, in the additive model, the frequencies of GA and AA genotypes at rs2296651 in CHB patients were significantly lower than HCs in both the $\mathrm{AOR}_{\mathrm{I}}$ (discovery group) and the $\mathrm{AOR}_{\mathrm{II}}$ (replication group), being 0.19 $(p<0.001)$ or $0.20(p<0.001)$, respectively (Table 2$)$.

Finally, the association between the rs2296651 mutant and HBV infection based on the merged data of the two groups was illustrated. Genetics analysis demonstrated that the rs2296651 mutant was inversely associated with HBV susceptibility, regardless of allele frequency $(\mathrm{OR}=0.19, \quad p<0.001)$, codominant model (AOR $=0.16, p<0.001)$, dominant model $(\mathrm{AOR}=0.18$, $p<0.001)$ or additive model (AOR $=0.19, p<0.001)$ (Table $2)$. The rs 2296651 mutant was inversely correlated with HBV susceptibility.

\section{Association between the rs943277 mutant and HBV susceptibility}

In the discovery group, the A allele for rs943277 was significantly higher in $\mathrm{CHB}$ patients than that in $\mathrm{HCs}$ $(3.0 \%$ vs $1.5 \%, \mathrm{OR}=3.17,95 \% \mathrm{CI}=1.14-8.8, p=0.019)$ (Table 2). In logistic regression analysis, the genotype frequencies of GA and AA were all significantly higher in $\mathrm{CHB}$ patients, using a codominant model $\left(\mathrm{AOR}_{\mathrm{I}}=2.80\right.$, $p=0.045)$, dominant model $\left(\mathrm{AOR}_{\mathrm{I}}=3.22, p=0.028\right)$ and additive model $\left(\mathrm{AOR}_{\mathrm{I}}=3.17, p=0.027\right)$ (Table 2$)$. In the replication group study, there was no significant statistical difference for the rs943277 mutant among CHB patients and HCs. The values of $\mathrm{AOR}_{\mathrm{II}}$ were $2.0(p=0.317), 1.92$ $(p=0.365)$ and $2.0(p=0.318)$, in codominant, dominant and additive genetics model, respectively (Table 2 ). When the data for the two groups were merged, the difference for the rs943277 mutant between $\mathrm{CHB}$ and HCs was statistically significant $(\mathrm{AOR}=2.66,95 \% \mathrm{CI}=1.17-6.01$, $p=0.014$ ) (Table 2). 
Table 1: Demographic and clinical features of the patients and healthy controls in the study

\begin{tabular}{|c|c|c|c|c|c|c|}
\hline & & & I & II & III & \\
\hline Characteristic & $\begin{array}{c}\text { HC } \\
(n=1232)\end{array}$ & Total $(n=1221)$ & $\begin{array}{l}\text { CHB without } \\
\text { LC and HCC } \\
\quad(n=866)\end{array}$ & $\begin{array}{l}\text { CHB with LC } \\
\qquad(\mathrm{n}=238)\end{array}$ & $\begin{array}{c}\text { CHB With HCC } \\
\qquad(n=117)\end{array}$ & $\begin{array}{c}p- \\
\text { value }\end{array}$ \\
\hline Mean Age $^{\dagger}$ & $46.51 \pm 13.81$ & $46.24 \pm 13.28$ & $44.16 \pm 13.72$ & $49.68 \pm 10.40$ & $54.60 \pm 10.22$ & 0.4188 \\
\hline Discover group & $42.18 \pm 12.45$ & $43.72 \pm 14.85$ & $43.17 \pm 15.19$ & $46.79 \pm 10.57$ & $52.80 \pm 14.87$ & 0.407 \\
\hline Replication group & $47.74 \pm 13.81$ & $46.89 \pm 12.78$ & $44.50 \pm 13.18$ & $50.00 \pm 10.36$ & $54.68 \pm 10.06$ & 0.16 \\
\hline $\begin{array}{l}\text { Gender (n, \%) } \\
\text { (Male/Female) }\end{array}$ & $\begin{array}{l}719(58.36) / \\
513(41.64)\end{array}$ & $\begin{array}{l}861(70.52) / \\
360(29.48)\end{array}$ & $\begin{array}{l}581(67.09) / \\
285(32.93)\end{array}$ & $\begin{array}{c}182(76.47) / \\
56(23.53)\end{array}$ & $\begin{array}{l}98(83.76) / \\
19(16.24)\end{array}$ & 0.077 \\
\hline Discover group & $\begin{array}{c}133(50.95) / \\
128(49.05)\end{array}$ & $\begin{array}{l}134(53.39) / \\
117(46.61)\end{array}$ & $\begin{array}{l}110(49.54) / \\
112(50.46)\end{array}$ & $\begin{array}{c}20(83.33) / \\
4(16.67)\end{array}$ & $\begin{array}{l}4(80.00) / \\
1(20.00)\end{array}$ & 0.185 \\
\hline Replication group & $\begin{array}{l}586(60.35) / \\
385(39.65)\end{array}$ & $\begin{array}{l}727(74.94) / \\
243(25.06)\end{array}$ & $\begin{array}{l}471(73.13) / \\
173(26.87)\end{array}$ & $\begin{array}{c}162(74.65) / \\
52(25.35)\end{array}$ & $\begin{array}{l}94(83.92) / \\
18(16.08)\end{array}$ & 0.075 \\
\hline $\mathbf{A} \mathbf{L} \mathbf{T}^{\dagger}$ & $20.52 \pm 9.166$ & $270.8 \pm 431.2$ & $341.0 \pm 488.1$ & $110.6 \pm 158.0$ & $87.21 \pm 163.8$ & $<0.0001$ \\
\hline Discover group & $22.15 \pm 9.217$ & $300.9 \pm 466.5$ & $335.2 \pm 499.7$ & $70.75 \pm 43.40$ & $97.40 \pm 70.07$ & $<0.0001$ \\
\hline Replication group & $20.08 \pm 9.108$ & $263.1 \pm 421.5$ & $342.9 \pm 484.6$ & $115.1 \pm 165.5$ & $86.76 \pm 166.9$ & $<0.0001$ \\
\hline $\mathbf{A S T}^{\dagger}$ & $19.35 \pm 4.969$ & $175.7 \pm 233.9$ & $200.9 \pm 263.4$ & $116.5 \pm 125.4$ & $110.2 \pm 119.3$ & $<0.0001$ \\
\hline Discover group & $21.14 \pm 4.706$ & $184.8 \pm 260.9$ & $197.9 \pm 279.3$ & $77.13 \pm 36.84$ & $117.2 \pm 91.42$ & $<0.0001$ \\
\hline Replication group & $18.87 \pm 4.929$ & $173.4 \pm 226.5$ & $201.9 \pm 258.2$ & $121.0 \pm 131.0$ & $109.9 \pm 120.7$ & $<0.0001$ \\
\hline $\mathbf{A F P}^{\dagger}$ & $1.945 \pm 1.715$ & $409.1 \pm 2336$ & $159.5 \pm 779.2$ & $182.4 \pm 367.9$ & $2262 \pm 6226$ & $<0.0001$ \\
\hline Discover group & $1.641 \pm 1.237$ & $217.8 \pm 1086$ & $149.2 \pm 823.8$ & $93.99 \pm 186.6$ & $3656 \pm 4543$ & $<0.0001$ \\
\hline Replication group & $2.008 \pm 1.749$ & $459.8 \pm 2554$ & $162.7 \pm 765.7$ & $229.4 \pm 410.7$ & $2205 \pm 6296$ & $<0.0001$ \\
\hline HBV-DNA (copies/ml) & & $(1.22 \pm 5.55) \times 10^{\wedge} 7$ & $(1.58 \pm 6.5) \times 10^{\wedge} 7$ & $4.07 \times 10^{\wedge} 6 \pm 1.56 \times 10^{\wedge} 7$ & $2.45 \times 10^{\wedge} 6 \pm 1.18 \times 10^{\wedge} 7$ & 0.002 \\
\hline$>100000(n, \%)$ & & $519(42.5)$ & $411(47.5)$ & $81(33.8)$ & $31(26.4)$ & \\
\hline Discover group & & $(1.97 \pm 7.03) \times 10^{\wedge} 7$ & $(2.18 \pm 7.41) \times 10^{\wedge} 7$ & $8.6 \times 10^{\wedge} 5 \pm 2.78 \times 10^{\wedge} 6$ & $9.71 \times 10^{\wedge} 6 \pm 1.11 \times 10^{\wedge} 7$ & 0.394 \\
\hline$>100000(\mathrm{n}, \%)$ & & $137(54.6)$ & $122(55.0)$ & $11(47.8)$ & $4(80)$ & \\
\hline Replication group & & $(1.03 \pm 5.1) \times 10^{\wedge} 7$ & $(1.37 \pm 6.15) \times 10^{\wedge} 7$ & $4.4 \times 10^{\wedge} 6 \pm 1.63 \times 10^{\wedge} 7$ & $2.12 \times 10^{\wedge} 6 \pm 1.11 \times 10^{\wedge} 7$ & 0.013 \\
\hline$>100000(\mathrm{n}, \%)$ & & $366(37.7)$ & $279(43.3)$ & $68(31.9)$ & $25(22.1)$ & \\
\hline $\mathbf{e A g}+(\mathrm{n}, \%)$ & / & $424(34.72)$ & $320(36.95)$ & $72(30.25)$ & $33(28.20)$ & l \\
\hline Discover group & / & $116(46.21)$ & $104(46.84)$ & $9(37.5)$ & $3(60.00)$ & 1 \\
\hline Replication group & / & $309(31.86)$ & $216(33.54)$ & $63(29.43)$ & $30(26.78)$ & l \\
\hline
\end{tabular}

CHB: chronic hepatitis B; LC: HBV-related liver cirrhosis; HCC: HBV-related hepatocellular carcinoma; HC: health control; ${ }^{\dagger}$ Date presented as (Mean $\pm \mathrm{SD}$ ); ${ }^{\ddagger} P$-value: $x^{2}$ test for all of all of CHB patients compared to HC individuals; Total group is the sum of group I, group II and group III.

\section{Other SNPs and HBV susceptibility}

As for rs17556915, rs9323529, rs943276 and rs4646296, there were no significant differences between $\mathrm{CHBs}$ and $\mathrm{HCs}$ in the discovery group, regardless of comparing allele frequencies or genotypes (Table 3).
Considering the lower minor allele frequency in CHBs and $\mathrm{HCs}(1.0 \%$ vs $0.4 \%, 0.4 \%$ vs $0.8 \%, 0.2 \%$ vs $0.8 \%$, and $9.2 \%$ vs $8.1 \%$ ), and non-statistically significant differences between the two groups (all $p>0.05$ ), it was not justified to further verify these SNP sites in the replication group (Table 3 ). 
Table 2: Association between rs2296651, rs943277 and HBV infection in Discovery and Replication group

\begin{tabular}{|c|c|c|c|c|c|c|c|c|c|c|c|c|c|c|}
\hline \multirow[b]{2}{*}{ Rs ID } & \multirow[b]{2}{*}{ Model } & \multirow[b]{2}{*}{ Genotype } & \multicolumn{3}{|c|}{ Discovery group } & \multirow[b]{2}{*}{$P_{1}$} & \multicolumn{3}{|c|}{ Replication group } & \multirow[b]{2}{*}{$P_{\mathrm{II}}$} & \multicolumn{3}{|c|}{ Total } & \multirow[b]{2}{*}{$\boldsymbol{P}_{\mathrm{T}}$} \\
\hline & & & $\begin{array}{c}\text { CHB } \\
\text { Patients }\end{array}$ & Controls & $\begin{array}{c}\mathrm{AOR}_{1}(95 \% \\
\text { CI })\end{array}$ & & $\begin{array}{c}\text { CHB } \\
\text { Patients }\end{array}$ & Controls & $\mathrm{AOR}_{\mathrm{II}}(95 \% \mathrm{CI})$ & & $\begin{array}{c}\text { CHB } \\
\text { Patients }\end{array}$ & Controls & $\mathrm{AOR}_{\mathrm{T}}(\mathbf{9 5} \% \mathrm{CI})$ & \\
\hline \multirow[t]{10}{*}{ rs2296651 } & Alleles & G & $492(98.0)$ & $455(90.3)$ & 1 & & $\begin{array}{c}1871 \\
(97.7)\end{array}$ & $1717(89.1)$ & 1 & & $2363(97.7)$ & $2172(89.3)$ & 1 & \\
\hline & & A & $10(2.0)$ & $49(9.7)$ & $\begin{array}{c}0.19 \\
(0.09-0.38)\end{array}$ & $<0.001$ & $45(2.3)$ & 211(10.9) & $\begin{array}{c}0.20 \\
(0.14-0.93)\end{array}$ & $<0.001$ & $55(2.3)$ & $260(10.7)$ & $\begin{array}{c}0.19 \\
(0.14-0.26)\end{array}$ & $<0.001$ \\
\hline & Codominant & GG & $241(96.0)$ & $203(80.6)$ & 1 & & $915(95.5)$ & $753(78.1)$ & 1 & & $1156(95.6)$ & $956(78.6)$ & 1 & \\
\hline & & GA & $10(4.0)$ & $49(19.4)$ & $\begin{array}{c}0.17 \\
(0.09-0.35)\end{array}$ & $<0.001$ & $41(4.3)$ & 211(21.9) & $\begin{array}{c}0.16 \\
(0.12-0.22)\end{array}$ & $<0.001$ & $51(4.2)$ & $260(21.4)$ & $\begin{array}{c}0.16 \\
(0.11-0.23)\end{array}$ & $<0.001$ \\
\hline & & AA & $0(0)$ & $0(0)$ & NA & NA & $2(0.2)$ & $0(0)$ & NA & NA & $2(0.2)$ & $0(0)$ & NA & NA \\
\hline & Dominant & $\mathrm{GG}+\mathrm{GA}$ & $251(100)$ & $252(100)$ & NA & NA & $956(99.8)$ & $964(100)$ & NA & NA & $1207(99.8)$ & $1216(100)$ & NA & NA \\
\hline & & AA & $0(0)$ & $0(0)$ & NA & NA & $2(0.2)$ & $0(0)$ & NA & NA & $2(0.2)$ & $0(0)$ & NA & NA \\
\hline & Recessive & $\mathrm{AA}+\mathrm{GA}$ & $10(4.0)$ & $49(19.4)$ & 1 & & $43(4.5)$ & 211(21.9) & 1 & & $53(4.4)$ & $260(21.4)$ & 1 & \\
\hline & & GG & 241(96.0) & 203(80.6) & $\begin{array}{c}0.17 \\
(0.08-0.34)\end{array}$ & $<0.001$ & $915(95.5)$ & 753(78.1) & $\begin{array}{c}0.19 \\
(0.14-0.28)\end{array}$ & $<0.001$ & 1156(95.6) & $956(78.6)$ & $\begin{array}{c}0.18 \\
(0.13-0.25)\end{array}$ & $<0.001$ \\
\hline & Additive & & & & $\begin{array}{c}0.17 \\
(0.08-0.37)\end{array}$ & $<0.001$ & & & $\begin{array}{c}0.21 \\
(0.15-0.29)\end{array}$ & $<0.001$ & & & $\begin{array}{c}0.19 \\
(0.16-0.26)\end{array}$ & $<0.001$ \\
\hline \multirow[t]{10}{*}{ rs943277 } & Alleles & G & $485(97.0)$ & $513(99.0)$ & 1 & & $\begin{array}{c}1932 \\
(99.7)\end{array}$ & $\begin{array}{c}1933 \\
(99.8)\end{array}$ & 1 & & $2417(99.1)$ & $2446(99.7)$ & 1 & \\
\hline & & A & $15(3.0)$ & $5(1.0)$ & $\begin{array}{c}3.17 \\
(1.14-8.80)\end{array}$ & 0.019 & $6(0.30)$ & $3(0.20)$ & $\begin{array}{c}2.0 \\
(0.50-8.02)\end{array}$ & 0.318 & $21(0.9)$ & $8(0.3)$ & $\begin{array}{c}2.66 \\
(1.17-6.01)\end{array}$ & 0.014 \\
\hline & Codominant & GG & $236(94.4)$ & $254(98.1)$ & 1 & & $963(99.4)$ & $965(99.7)$ & 1 & & 1199(98.4) & $1219(99.3)$ & 1 & \\
\hline & & GA & $13(5.2)$ & $5(1.9)$ & $\begin{array}{c}2.80(0.98- \\
7.97)\end{array}$ & 0.045 & $6(0.60)$ & $3(0.30)$ & $\begin{array}{c}2.0 \\
(0.50-8.04)\end{array}$ & 0.317 & $19(1.6)$ & $8(0.7)$ & $\begin{array}{c}2.42 \\
(1.05-5.54)\end{array}$ & 0.032 \\
\hline & & AA & $1(0.4)$ & $0(0)$ & $\begin{array}{c}0.31(0.01- \\
7.65)\end{array}$ & 0.3 & $0(0)$ & $0(0)$ & NA & NA & $1(0)$ & $0(0)$ & NA & NA \\
\hline & Dominant & $\mathrm{GG}+\mathrm{GA}$ & $249(99.6)$ & $259(100.0)$ & 1 & & $969(100.0)$ & $968(100.0)$ & NA & NA & 1218(99.9) & $1227(100)$ & NA & NA \\
\hline & & AA & $1(0.4)$ & $0(0)$ & NA & NA & $0(0)$ & $0(0)$ & NA & NA & $1(0.1)$ & $0(0)$ & NA & NA \\
\hline & Recessive & $\mathrm{AA}+\mathrm{GA}$ & $14(5.6)$ & $5(1.9)$ & 1 & & $6(0.60)$ & $3(0.30)$ & 1 & & $20(1.6)$ & $8(0.7)$ & 1 & \\
\hline & & GG & $236(94.4)$ & 254(98.1) & $\begin{array}{c}3.22 \\
(1.13-9.19)\end{array}$ & 0.028 & $963(99.4)$ & $965(99.7)$ & $\begin{array}{c}1.92 \\
(0.47-7.89)\end{array}$ & 0.365 & 1199(98.4) & $1219(99.3)$ & $\begin{array}{c}2.32 \\
(1.01-5.34)\end{array}$ & 0.048 \\
\hline & Additive & & & & $\begin{array}{c}3.17 \\
(1.13-8.84)\end{array}$ & 0.027 & & & $\begin{array}{c}1.92 \\
(0.47-7.89)\end{array}$ & 0.365 & & & $\begin{array}{c}2.34 \\
(1.05-5.22)\end{array}$ & 0.039 \\
\hline
\end{tabular}

Data were presented as number (percentage) for every group. The differences of genotype frequencies among groups were analyzed using logistic regression models (Codominant, Recessive, Dominant, additive). Age and sex were included as covariates. AORs (adjusted odds ratio) were calculated and reported within the $95 \% \mathrm{CI}$ (confidence interval). AOR, $\mathrm{AOR}_{\mathrm{II}}$ and $\mathrm{AOR}_{\mathrm{T}}$ were calculated for discovery group, replication group and total of patients, respectively. Significant p-values $(p<0.05)$ are highlighted in bold.

\section{Meta-analysis of the association between NTCP polymorphisms and HBV susceptibility}

Based on our current data and systematic review of other studies up to date, meta-analysis was adopted to illuminate the association between these host genetic mutants of NTCP and HBV susceptibility. In total, 9 studies were extracted for meta-analysis, including 7 studies $[10-14,16,17]$ and our data focused on rs2296651, 4 studies $[13,14,16,18]$ on rs 4646287,4 studies $[14,16$, $18,19]$ on rs 7154439 and 2 studies $[14,18]$ linked with our data on rs4646296. Quality assessment showed the high quality of the included studies. The host genetics characteristics as well as the quality scores of the included studies are illustrated in Supplementary Table 4 and Supplementary Table 3.

Meta-analysis was performed to assess the association between rs2296651 and HBV infection, including CHB patients ( $\mathrm{n}=12303)$ and HCs $(\mathrm{n}=10593)$. Although the number of people included was not fully achieved to meet the required sample size to undertake trial sequential analysis (TSA)[20], the gap was small enough to be ignored (actual sample size/required sample size $=20958 / 21464$ ) based on the pre-set $90 \%$ power. Furthermore, the cumulative Z-curve had crossed the monitoring boundaries (red lines), confirming our data were reliable (Figure 1).

Considering high heterogeneity among the included reports (shown in Table 4 and Figure 2), a random effect model and genetics model analysis were adopted to assess the data. There were lower $\mathrm{A}$ allele frequencies in the CHB group $(\mathrm{OR}=0.607,95 \% \mathrm{CI}=0.388-0.948$, $p=0.028$ ) compared with HCs group. The GA frequency of rs2296651 in CHB patients was significantly lower than that in HCs. The OR for GA in the codominant model analysis was $0.593(95 \% \mathrm{CI}=0.376-0.937, p=0.025)$ 
Table 3: Association between 4 loci of NTCP mutant and HBV infection in discovery group

\begin{tabular}{|c|c|c|c|c|c|c|}
\hline Rs ID & Model & Genotype & Patients & Control & $\operatorname{AOR}(95 \% \mathrm{CI})$ & $p$ \\
\hline \multirow[t]{10}{*}{ rs17556915 } & Alleles & G & $495(99.0)$ & $520(99.6)$ & 1 & \\
\hline & & A & $5(1.0)$ & $2(0.4)$ & $2.63(0.507-13.6)$ & 0.232 \\
\hline & Codominant & GG & $245(98.0)$ & 259(99.2) & 1 & \\
\hline & & GA & $5(2.0)$ & $2(0.8)$ & $2.643(0.5078-13.75)$ & 0.23 \\
\hline & & AA & $0(0)$ & $0(0)$ & NA & NA \\
\hline & Dominant & $\mathrm{GG}+\mathrm{GA}$ & $250(100.0)$ & $261(100.0)$ & 1 & \\
\hline & & AA & $0(0)$ & $0(0)$ & NA & NA \\
\hline & Recessive & $\mathrm{AA}+\mathrm{GA}$ & $5(2.0)$ & $2(0.8)$ & 1 & \\
\hline & & GG & $245(98.0)$ & 259(99.2) & $2.83(0.537-14.9)$ & 0.22 \\
\hline & Additive & & & & $2.83(0.537-14.9)$ & 0.22 \\
\hline \multirow[t]{10}{*}{ rs4646296 } & Alleles & G & $452(90.8)$ & 478 (91.9) & 1 & \\
\hline & & $\mathrm{C}$ & $46(9.2)$ & $42(8.1)$ & $1.16(0.748-1.79)$ & 0.51 \\
\hline & Codominant & GG & $205(82.0)$ & $220(84.6)$ & 1 & \\
\hline & & $\mathrm{GC}$ & $44(17.6)$ & $38(14.6)$ & $1.243(0.774-1.99)$ & 0.368 \\
\hline & & $\mathrm{CC}$ & $1(0.4)$ & $2(0.8)$ & $1.86(0.168-20.72)$ & 0.607 \\
\hline & Dominant & $\mathrm{GG}+\mathrm{GC}$ & 249 (99.6) & 258(99.2) & 1 & \\
\hline & & $\mathrm{CC}$ & $1(0.4)$ & $2(0.8)$ & $0.441(0.039-4.98)$ & 0.508 \\
\hline & Recessive & $\mathrm{CC}+\mathrm{GC}$ & $45(18.0)$ & $40(15.4)$ & 1 & \\
\hline & & GG & $205(82.0)$ & $220(84.6)$ & $1.16(0.720-1.86)$ & 0.547 \\
\hline & Additive & & & & $1.11(0.705-1.73)$ & 0.661 \\
\hline \multirow[t]{10}{*}{ rs9323529 } & Alleles & $\mathrm{T}$ & $500(99.6)$ & $516(99.2)$ & 1 & \\
\hline & & G & $2(0.4)$ & $4(0.8)$ & $0.516(0.094-2.83)$ & 0.438 \\
\hline & Codominant & TT & 249 (99.2) & $256(98.5)$ & 1 & \\
\hline & & $\mathrm{TG}$ & $2(0.8)$ & $4(1.5)$ & $0.514(0.093-2.83)$ & 0.44 \\
\hline & & GG & $0(0)$ & $0(0)$ & NA & NA \\
\hline & Dominant & $\mathrm{TT}+\mathrm{TG}$ & $251(100.0)$ & $260(100.0)$ & 1 & \\
\hline & & GG & $0(0)$ & $0(0)$ & NA & NA \\
\hline & Recessive & $\mathrm{GG}+\mathrm{TG}$ & $2(0.8)$ & $4(1.5)$ & 1 & \\
\hline & & $\mathrm{TT}$ & $249(99.2)$ & $256(98.5)$ & $0.537(0.097-2.98)$ & 0.477 \\
\hline & Additive & & & & $0.537(0.097-2.98)$ & 0.477 \\
\hline \multirow[t]{10}{*}{ rs943276 } & Alleles & G & 499 (99.8) & $514(99.2)$ & 1 & \\
\hline & & A & $1(0.2)$ & $4(0.8)$ & $0.258(0.029-2.31)$ & 0.191 \\
\hline & Codominant & GG & 249(99.6) & $255(98.5)$ & 1 & \\
\hline & & GA & $1(0.4)$ & $4(1.5)$ & $0.256(0.028-2.31)$ & 0.191 \\
\hline & & AA & $0(0)$ & $0(0)$ & NA & NA \\
\hline & Dominant & $\mathrm{GG}+\mathrm{GA}$ & $250(100.0)$ & $259(100.0)$ & 1 & \\
\hline & & AA & $0(0)$ & $0(0)$ & NA & NA \\
\hline & Recessive & $\mathrm{AA}+\mathrm{GA}$ & $1(0.4)$ & $4(1.5)$ & 1 & \\
\hline & & GG & 249(99.6) & $255(98.5)$ & $0.268(0.029-2.44)$ & 0.242 \\
\hline & Additive & & & & $0.268(0.029-2.44)$ & 0.242 \\
\hline
\end{tabular}

AOR, adjusted odds ratio; CI, confidence interval. Data were presented as number (percentage) for every group. The differences in genotype frequencies between any two groups were analyzed using logistic regression models (Codominant, Recessive, Dominant, additive). Age and sex were included as covariates. AORs were calculated and reported within the $95 \%$ CI. Significant p-values $(p<0.05)$ are highlighted in bold. 
and in the recessive model was 0.59 , $(95 \% \mathrm{CI}=0.370$ $0.941, p=0.027$ ). In the overdominant model (GA vs $\mathrm{GG}+\mathrm{AA}$ ), the OR was 0.595 and also suggested that the GA frequency was lower in the CHB group. All of these results demonstrated that GA-rs2296651 was inversely correlated with HBV infection.

As for rs4646287, rs7154439 and rs4646296, a fixed effects model was adopted because low heterogeneity existed among all the included studies $\left(\mathrm{I}^{2}<50 \%\right)$. Metaanalysis from the combined 3 reports showed no correlation between the rs4646287 polymorphism and HBV infection, including CHB patients $(n=5488)$ and HCs $(n=3996)$ (Table 4 or Supplementary Figure 1). There was no significant difference between CHB patients $(n=4465)$ and HCs $(n=4157)$ for rs7154439 variation (Table 4 or Supplementary Figure 1). Similarly, there was no correlation between rs4646296 mutants and HBV infection in the genetics model analysis (2479 CHBs vs 2399 HCs) (Table 4 or Supplementary Figure 1).
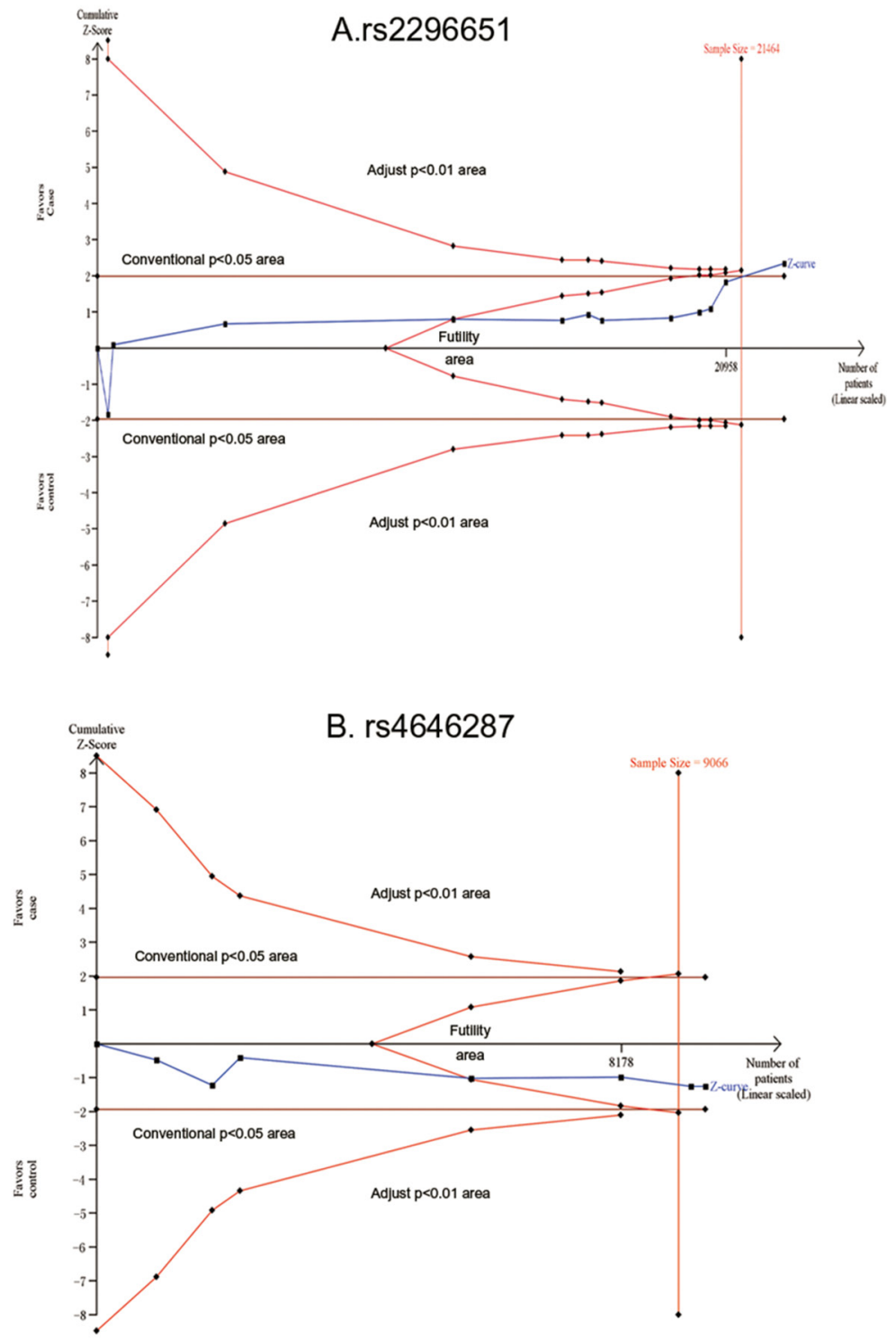

Figure 1: Trial sequential analysis: Gene mutation in NTCP association with HBV infection risk. The blue line indicated the $\mathrm{Z}$ curve (cumulative effect size), the red curves represented the harm, benefit, and futility boundaries, the red vertical line is the adjusted optimal sample size, the brick-red lines represent the conventional confidence intervals. The black number and marking in the X-axis is the actual number of samples size included in the meta-analysis. The heterogeneity-adjusted sample size based on power of 0.90 , $(\alpha=5 \%$ and $\beta=10 \%$ ) were 21464,9066 . (A) Although the number of the participants had not achieved the required size, the gap is small enough to be ignored (20958 vs 21464) and the cumulative Z-curve had crossed the monitoring boundaries. Sufficient evidence suggested rs2296651GA genotype negatively association with HBV infection risk. (B) The actual samples did not meet the required size for rs4646287 (8178 vs 9066), which the gap was negligible. The cumulative Z-curve had not crossed the monitoring boundaries suggested that the evidence of rs4646287-GA genotype negatively association with HBV infection risk is insufficient. 
Table 4: Meta-analysis of association between rs2296651, rs4646287, rs7154439, rs4646296 polymorphism and HBV infection

\begin{tabular}{|c|c|c|c|c|c|c|c|c|c|c|}
\hline RsID & Model & Comparison & Studies & $I^{2}(\%)$ & Model & OR $(95 \%$ CI) & $p 1$ & $p 2$ & p3 & $p 4$ \\
\hline \multirow[t]{7}{*}{ rs2296651 } & Alleles & G vs A & 8 & $95.3 \%$ & Random & $\begin{array}{c}0.607 \\
(0.388,0.948)\end{array}$ & 0.028 & 0.001 & 0.346 & 0.468 \\
\hline & Codominant & GA vs GG & 8 & $94.9 \%$ & Random & $\begin{array}{c}0.593 \\
(0.376,0.937)\end{array}$ & 0.025 & 0.001 & 0.394 & 0.532 \\
\hline & Codominant & GG vs AA & 8 & $87.0 \%$ & Random & $\begin{array}{c}1.656 \\
(0.232,11.83)\end{array}$ & 0.615 & 0.001 & 0.692 & 0.587 \\
\hline & Dominant & $\mathrm{GG}+\mathrm{GA}$ vs $\mathrm{AA}$ & 8 & $86.4 \%$ & Random & $\begin{array}{c}0.654 \\
(0.096,4.466)\end{array}$ & 0.665 & 0.001 & 0.695 & 0.590 \\
\hline & Recessive & $\mathrm{GG}$ vs $\mathrm{AA}+\mathrm{GA}$ & 8 & $95.2 \%$ & Random & $\begin{array}{c}0.590 \\
(0.370,0.941)\end{array}$ & 0.027 & 0.001 & 0.376 & 0.505 \\
\hline & Overdominant & $\mathrm{GG}+\mathrm{AA}$ vs GA & 8 & $94.8 \%$ & Random & $\begin{array}{c}0.595 \\
(0.378,0.936)\end{array}$ & 0.025 & 0.001 & 0.399 & 0.538 \\
\hline & Additive & & 8 & $95.3 \%$ & Random & $\begin{array}{c}0.607 \\
(0.388,0.948)\end{array}$ & 0.028 & 0.001 & 0.346 & 0.468 \\
\hline \multirow[t]{7}{*}{ rs4646287 } & Alleles & G vs A & 4 & $0.01 \%$ & Fixed & $\begin{array}{c}0.995 \\
(0.900,1.102)\end{array}$ & 0.929 & 0.432 & 0.188 & 0.204 \\
\hline & Codominant & GA vs GG & 4 & $31.9 \%$ & Fixed & $\begin{array}{c}0.962 \\
(0.860,1.075)\end{array}$ & 0.492 & 0.184 & 0.064 & 0.073 \\
\hline & Codominant & GG vs AA & 4 & $0.01 \%$ & Fixed & $\begin{array}{c}0.769 \\
(0.501,1.183)\end{array}$ & 0.232 & 0.552 & 0.893 & 0.595 \\
\hline & Dominant & $\mathrm{GG}+\mathrm{GA}$ vs $\mathrm{AA}$ & 4 & $0.01 \%$ & Fixed & $\begin{array}{c}1.310 \\
(0.853,2.012)\end{array}$ & 0.217 & 0.534 & 0.852 & 0.564 \\
\hline & Recessive & $\mathrm{GG}$ vs $\mathrm{AA}+\mathrm{GA}$ & 4 & $17.5 \%$ & Fixed & $\begin{array}{c}1.023 \\
(0.917,1.142)\end{array}$ & 0.678 & 0.296 & 0.101 & 0.113 \\
\hline & Overdominant & $\mathrm{GG}+\mathrm{AA}$ vs GA & 4 & $33.3 \%$ & Fixed & $1.044(0.933,1.167)$ & 0.452 & 0.174 & 0.062 & 0.072 \\
\hline & Additive & G vs A & 4 & $0.01 \%$ & Fixed & $\begin{array}{c}0.995 \\
(0.900,1.102)\end{array}$ & 0.929 & 0.432 & 0.188 & 0.204 \\
\hline \multirow[t]{7}{*}{ rs7154439 } & Alleles & G vs A & 4 & $29.9 \%$ & Fixed & $\begin{array}{c}1.027 \\
(0.948,1.112)\end{array}$ & 0.514 & 0.189 & 0.524 & 0.502 \\
\hline & Codominant & GA vs GG & 4 & $34.2 \%$ & Fixed & $\begin{array}{c}1.059 \\
(0.962,1.165)\end{array}$ & 0.240 & 0.156 & 0.988 & 0.992 \\
\hline & Codominant & GG vs AA & 4 & $26.2 \%$ & Fixed & $\begin{array}{c}1.053 \\
(0.828,1.339)\end{array}$ & 0.672 & 0.219 & 0.219 & 0.227 \\
\hline & Dominant & $\mathrm{GG}+\mathrm{GA}$ vs $\mathrm{AA}$ & 4 & $26.3 \%$ & Fixed & $0.933(0.735,1.185)$ & 0.570 & 0.219 & 0.215 & 0.228 \\
\hline & Recessive & $\mathrm{GG}$ vs $\mathrm{AA}+\mathrm{GA}$ & 4 & $32.2 \%$ & Fixed & $0.955(0.871,1.047)$ & 0.330 & 0.171 & 0.763 & 0.747 \\
\hline & Overdominant & $\mathrm{GG}+\mathrm{AA}$ vs GA & 4 & $34.2 \%$ & Fixed & $0.942(0.857,1.036)$ & 0.219 & 0.155 & 0.875 & 0.896 \\
\hline & Additive & G vs A & 4 & $29.9 \%$ & Fixed & $1.027(0.948,1.112)$ & 0.514 & 0.189 & 0.524 & 0.502 \\
\hline \multirow[t]{7}{*}{ rs4646296 } & Alleles & G vs C & 3 & $0.01 \%$ & Fixed & $1.018(0.896,1.157)$ & 0.781 & 0.843 & 0.871 & 0.873 \\
\hline & Codominant & GC vs GG & 3 & $0.01 \%$ & Fixed & $1.017(0.882,1.171)$ & 0.821 & 0.823 & 0.657 & 0.654 \\
\hline & Codominant & GG vs $\mathrm{CC}$ & 3 & $0.01 \%$ & Fixed & $0.937(0.528,1.664)$ & 0.825 & 0.545 & 0.201 & 0.233 \\
\hline & Dominant & $\mathrm{GG}+\mathrm{GC}$ vs $\mathrm{CC}$ & 3 & $0.01 \%$ & Fixed & $1.062(0.599,1.883)$ & 0.837 & 0.541 & 0.185 & 0.217 \\
\hline & Recessive & $\mathrm{GG}$ vs $\mathrm{CC}+\mathrm{GC}$ & 3 & $17.5 \%$ & Fixed & $0.982(0.854,1.129)$ & 0.800 & 0.837 & 0.870 & 0.871 \\
\hline & Overdominant & $\mathrm{GG}+\mathrm{CC}$ vs GC & 3 & $0.01 \%$ & Fixed & $0.985(0.855,1.135)$ & 0.837 & 0.819 & 0.604 & 0.607 \\
\hline & Additive & G vs C & 3 & $0.01 \%$ & Fixed & $1.018(0.896,1.157)$ & 0.781 & 0.843 & 0.871 & 0.873 \\
\hline
\end{tabular}

$\mathrm{I}^{2}$, variation in OR attributable to heterogeneity; OR, odds ratio; $95 \%$ CI, 95\% confidence interval; Random, random effects model; $p 1, \mathrm{p}$ value for OR; $p 2$, $\mathrm{p}$ value for heterogeneity; $p 3, p 4$, Egger test and Harbord test for publication bias; Bold values are statistically significant $(p<0.05)$; Na, not available. 
In the trial sequential analysis, sample size of the 3 loci (rs4646287, rs7154439 and rs4646296) did not meet the required level (actual sample size vs required sample size: 8178 vs 9066,3971 vs 6845 and 2682 vs 7721$)$. The cumulative Z-curve of these variations did not surpass the monitoring boundaries (data not shown).

\section{Publication bias}

Although the funnel plot indicated evidence of certain asymmetry because of high heterogeneity, there was no potential publication bias existed among all conclusions of these mutants through calculating Harbord' test, Egger's test or Begg's test (all $p>0.05$ ) (Figure 3 and Table 4).

\section{Grading of GRADE and credibility of meta-analysis results}

Based on the Venice Guidelines of Recommendations Assessment, Development and
Evaluation of quality, credibility of the association of the variants of NTCP with HBV infection were calculated by GRADEpro software. Due to observational studies, inconsistency risk, small number of studies as well as smaller sample sizes, the quality of evidence for rs2296651, rs4646287, rs7154439 and rs4646296 mutants were graded as moderate quality. Finally, GRADE result demonstrated evidence for the association between rs2296651 variants and HBV infection, and was ranked as moderate and the conclusion was identified as critical (very important) grade. In addition, evidences of rs4646287, rs7154439 and rs4646296 were ranked as moderate and the conclusions were viewed as important grades (as presented in Supplementary Figure 2).

\section{Inverse association between NTCP rs2296651 mutant and HBV-related LC/HCC}

To assess the association between rs2296651 and LC/HCC, patients with LC or HCC were compared with healthy individuals and $\mathrm{CHB}$ (patients without
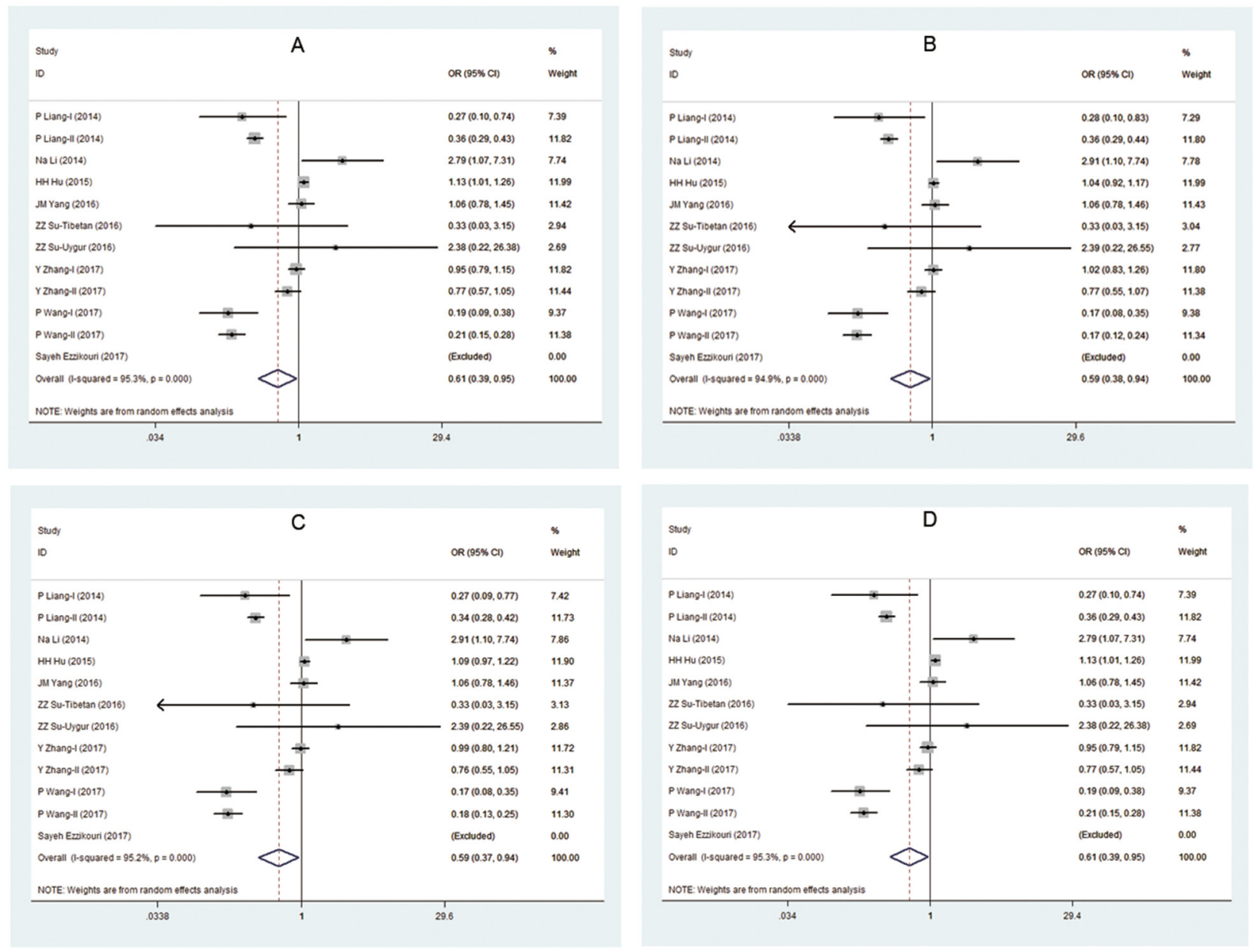

Figure 2: Forest plots show odds ratio (OR) for the associations between NTCP variations (rs2296651) and HBV infection. (A) allele model (G vs A); (B) heterozygote model (GA vs GG); (C) recessive model (AA+GA vs GG); (D) additive model. 
liver cirrhosis and HCC), respectively. The frequency of rs2296651-GA was lower in LC or HCC patients [adjusted $\mathrm{OR}(95 \% \mathrm{CI})=(0.21-0.55), p=0.001$; or $0.46(0.25-0.83)$, $p=0.008]$, compared with HCs, using multivariate logistic analysis (Table 5). Logistic analysis also showed that participants with the GA genotype of the rs2296651 mutant had increase risk of being in the LC group (adjust OR $(95 \% \mathrm{CI})$, which was 2.033(1.083-3.818), $p=0.027$,
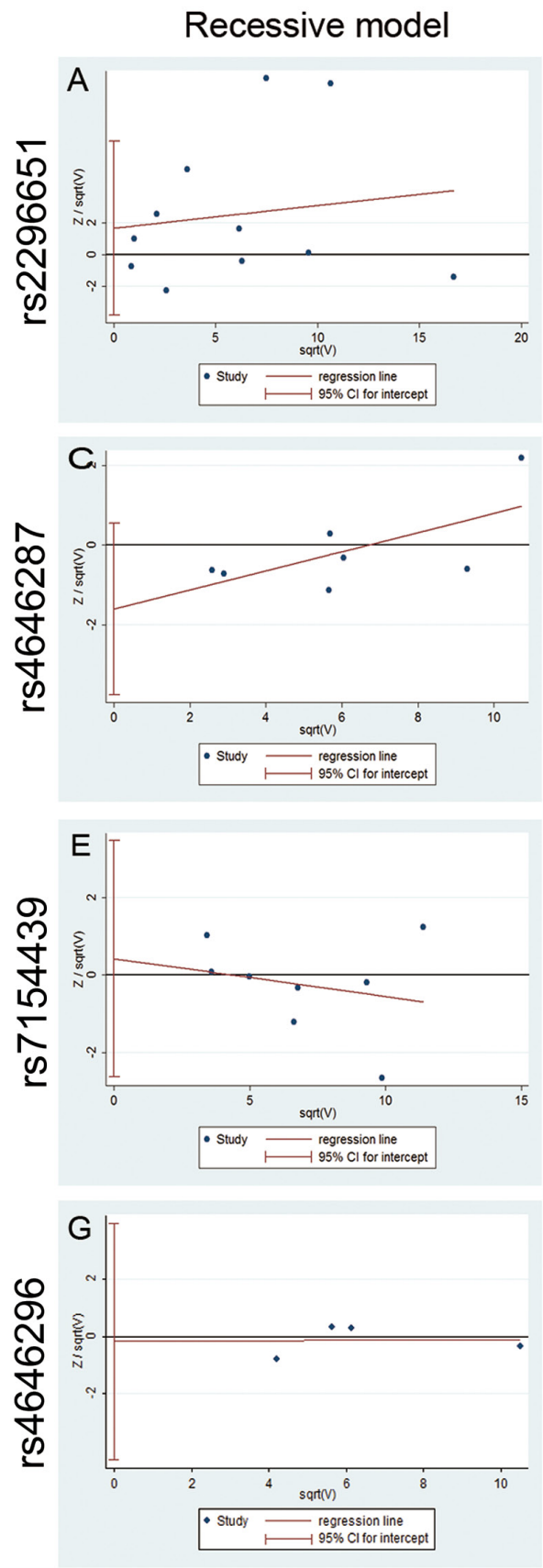

dominant model), compared with the CHB group (Table $5)$. However, there were no significantly association of the rs2296651-GA mutant between the HCC group and CHB group [AOR $(95 \% \mathrm{CI})$ which was 0.889(0.290-2.731), $p=0.837$, dominant model], due to the relatively small sample size (Table 5).

However, it was observed that the inverse association between mutant rs2296651 and HCC was
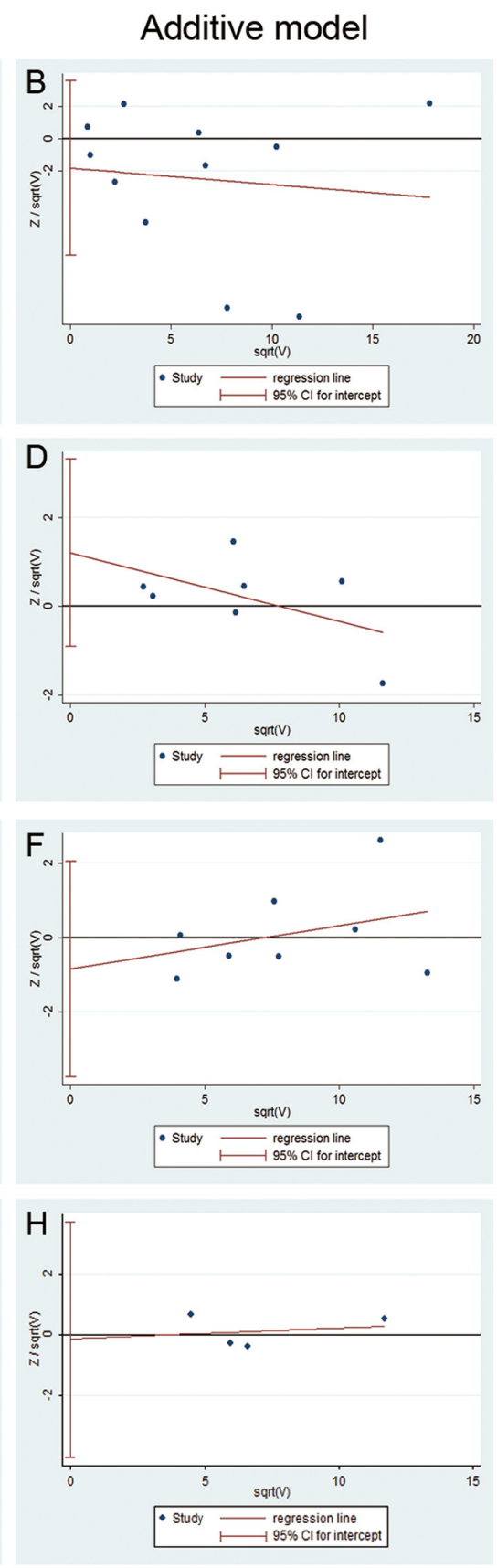

Figure 3: Funnel plot for publish bias in selection of studies on the polymorphism of NTCP and HBV infection (recessive and additive model). (A, B) The publish bias between the rs2296651 polymorphism and risk of HBV infection (recessive model) and (additive model). (C, D) The publish bias between the rs4646287 polymorphism and risk of HBV infection (recessive model) and (additive model). (E, F) The publish bias between the rs7154439 polymorphism and risk of HBV infection (recessive model) and (additive model). (G, H) The publish bias between the rs4646296 polymorphism and risk of HBV infection (recessive model) and (additive model). 
Table 5: Association between rs2296651 and LC, HCC in present study

\begin{tabular}{|c|c|c|c|c|c|c|c|c|c|c|c|c|c|c|}
\hline RS ID & Model & Genotype & $\mathrm{HC}$ & CHB & LC & $\mathrm{HCC}$ & $\mathrm{AOR}_{1}$ & $P_{1}$ & $\mathrm{AOR}_{2}$ & $P_{2}$ & $\mathrm{AOR}_{3}$ & $P_{3}$ & $\mathrm{AOR}_{4}$ & $P_{4}$ \\
\hline \multirow[t]{10}{*}{ rs2296651 } & Alleles & G & $2172(89.3)$ & $1682(98.5)$ & $452(95.4)$ & $229(97.9)$ & 1 & & 1 & & 1 & & 1 & \\
\hline & & A & $260(10.7)$ & $26(1.5)$ & $22(4.6)$ & $5(2.1)$ & $\begin{array}{c}0.532 \\
(0.328-0.861)\end{array}$ & 0.01 & $\begin{array}{c}1.95 \\
(1.08-3.521)\end{array}$ & 0.026 & $\begin{array}{c}0.519 \\
(0.273-0.99)\end{array}$ & 0.046 & $\begin{array}{c}0.866 \\
(0.292- \\
2.575)\end{array}$ & 0.796 \\
\hline & Codominant & GG & $956(78.6)$ & $828(96.8)$ & $216(90.8)$ & $112(95.7)$ & 1 & & 1 & & 1 & & 1 & \\
\hline & & GA & $260(21.4)$ & $26(3.0)$ & $20(8.4)$ & $5(4.3)$ & $\begin{array}{c}0.341 \\
(0.211-0.549)\end{array}$ & 0.001 & $\begin{array}{c}2.934 \\
(1.607-5.358)\end{array}$ & 0.003 & $\begin{array}{c}0.46 \\
(0.254-0.832)\end{array}$ & 0.008 & $\begin{array}{c}1.422 \\
(0.535- \\
3.778)\end{array}$ & 0.484 \\
\hline & & $\mathrm{AA}$ & $0(0)$ & $1(0.1)$ & $1(0.8)$ & $0(0)$ & NA & NA & NA & NA & NA & NA & & \\
\hline & Dominant & $\mathrm{GG}+\mathrm{GA}$ & $1216(100)$ & 854(99.9) & $236(99.2)$ & 117(100) & 1 & & 1 & & 1 & & 1 & \\
\hline & & $\mathrm{AA}$ & $0(0)$ & $1(0.1)$ & $1(0.8)$ & $0(0)$ & NA & NA & $\begin{array}{c}2.033 \\
(1.083-3.818)\end{array}$ & 0.027 & NA & NA & $\begin{array}{c}0.889 \\
(0.290- \\
2.731)\end{array}$ & 0.837 \\
\hline & Recessive & $\mathrm{AA}+\mathrm{GA}$ & $260(21.4)$ & $27(3.1)$ & $21(8.8)$ & $5(4.3)$ & 1 & & 1 & & 1 & & 1 & \\
\hline & & GG & $956(78.6)$ & $828(96.9)$ & $216(91.2)$ & $112(95.7)$ & $\begin{array}{c}0.499 \\
(0.306-0.818)\end{array}$ & 0.001 & $\begin{array}{c}2.994 \\
(0.186-48.26)\end{array}$ & 0.44 & $\begin{array}{c}0.52 \\
(0.273-0.99)\end{array}$ & 0.041 & NA & NA \\
\hline & Additive & & & & & & $\begin{array}{c}0.532 \\
(0.328-0.861)\end{array}$ & 0.01 & $\begin{array}{c}1.95 \\
(1.08-3.521)\end{array}$ & 0.026 & $\begin{array}{c}0.519 \\
(0.273-0.99)\end{array}$ & 0.046 & $\begin{array}{c}0.866 \\
(0.292- \\
2.575)\end{array}$ & 0.796 \\
\hline
\end{tabular}

LC, liver cirrhosis. HCC, hepatocellular carcinoma. Data were presented as number (percentage) for every group. The differences in genotype frequencies between any two groups were analyzed using logistic regression models (Codominant, Recessive, Dominant, additive). Age and sex were included as covariates. AOR ${ }_{1}$ and $P_{1}$ Comparison of patients with LC to HC. AOR, and $P_{2}$, Comparison of patients with $\mathrm{LC}$ to $\mathrm{CHB} . \mathrm{AOR}_{3}$ and $P_{3}$, Comparison of patients with $\mathrm{HCC}$ to $\mathrm{HC}$. $\mathrm{AOR}_{4}$ and $P_{4}$, Comparison of patients with $\mathrm{HCC}$ to $\mathrm{CHB}$. AOR( $(95 \% \mathrm{CI})$, adjusted odds ratio was calculated and reported within the $95 \%$ confidence interval. Significant $p$-values $(p<0.05)$ were highlighted in bold.

present, OR is $0.701(p=0.001$, recessive model $)$, when analysed by systematic review and meta-analysis ( 2 studies and our data; characteristics of the included studies are shown in Supplementary Table 5), including HCC patients ( $n=956)$ and CHB patients $(n=3759)$, (Table 6). To evaluate the association between rs2296651 and LC, the LC patients $(\mathrm{n}=938)$ were compared to the CHB patients $(n=3759)$. Meta-analysis demonstrated no significant association between rs2296651 and the LC patients, which might be due to high heterogeneity (Table 6). The Harbored' test and Egger' test of meta-analysis further confirmed no publication bias (Table 6). These results of meta-analysis suggest a significant inversely association between rs2296651-GA genotype and HCC patients, but not cirrhosis.

\section{DISCUSSION}

In the present study, NTCP polymorphisms were investigated in $\mathrm{CHB}$ and $\mathrm{HBV}$-related $\mathrm{HCC}$ patients among the Chinese Han population. The NTCP rs2296651-GA variant was inversely correlated with susceptibility to HBV infection or HBV-related HCC. It was confirmed that individuals who carry the rs2296651GA genotype have a lower risk of HBV infection than those of the GG genotype, suggesting a possible protective role of this variant (rs2296651-GA) during HBV infection. The association between the rs2296651 mutant and HCC was further investigated, demonstrating that participants with the rs2296651-GA genotype have lower risk of HCC compared with individuals who carry the GG genotype. These associations were then verified using meta-analysis.
In addition, the GA genotype of the rs943277 mutant on NTCP has for the first time been revealed to be a potential hazardous mutant, facilitating susceptibility to HBV infection. However, there was no association among other variants (rs17556915, rs4646296, rs9323529, rs943277, rs4646287 and rs7154439) with HBV susceptibility or HCC. Our current study is the first systemic review and meta-analysis that focused on the association between NTCP polymorphisms and HBV susceptibility or HBVrelated $\mathrm{HCC}$.

NTCP is a functional receptor for HBV entry in vitro [6], which is supported by the findings that $\mathrm{HBV}$ entrance is blocked via inhibiting NTCP in hepatocyte using cyclosporine A [21] and that tent-making bat HBV (TBHBV) can infect human hepatocytes via the human NTCP (hNTCP) receptor [22, 23]. Moreover, the species specificity and hepatotropism of $\mathrm{HBV}$ infection were determined by the functional receptor restrictions [24-26]. Our data and other gene association studies [10-13] have further verified the role of NTCP in HBV susceptibility from the perspective of genetics correlation in vivo.

HBV susceptibility in certain populations is partially influenced by ethnic difference [27] and gene polymorphism [28]. The rs2296651 (S267F) mutation leads to an amino acid change in human NTCP, resulting in functional alterations of NTCP [28]. The GA mutant on rs2296651 has been identified as an Asia-specific variant among Asia countries [29]. When linked to the high prevalence of $\mathrm{HBV}$ infection in Asia, especially in China, it was of great interest to determine the association between the rs2296651 mutant and HBV susceptibility in these regions. However, the association study 
Table 6: Meta-analysis of association between rs2296651 polymorphism and HBV-related LC or HCC

\begin{tabular}{|c|c|c|c|c|c|c|c|c|c|c|c|}
\hline RsID & Patients & $\begin{array}{c}\text { Genetic } \\
\text { Model }\end{array}$ & Comparison & Studies & $\begin{array}{c}I^{2} \\
(\%)\end{array}$ & $\begin{array}{c}\text { Meta } \\
\text { Model }\end{array}$ & OR $(95 \%$ CI) & p1 & p2 & p3 & p4 \\
\hline \multirow[t]{3}{*}{ rs2296651 } & $\mathbf{L C}$ & Alleles & G vs A & 3 & 90.5 & Random & $\begin{array}{c}1.374 \\
(0.519,3.643)\end{array}$ & 0.522 & 0.001 & 0.431 & 0.391 \\
\hline & & Codominant & GA vs GG & 3 & 89.7 & Random & $\begin{array}{c}1.376 \\
(0.514,3.686)\end{array}$ & 0.525 & 0.001 & 0.415 & 0.378 \\
\hline & & Recessive & $\begin{array}{c}\text { GG vs } \\
\mathrm{AA}+\mathrm{GA}\end{array}$ & 3 & 90.3 & Random & $\begin{array}{c}1.380 \\
(0.506,3.763)\end{array}$ & 0.529 & 0.009 & 0.424 & 0.385 \\
\hline \multirow[t]{3}{*}{ rs2296651 } & $\mathrm{HCC}$ & Alleles & G vs A & 3 & 28.9 & Fixed & $\begin{array}{c}0.722 \\
(0.562,0.837)\end{array}$ & 0.002 & 0.245 & 0.129 & 0.113 \\
\hline & & Codominant & GA vs GG & 3 & 35.0 & Fixed & $\begin{array}{c}0.701 \\
(0.564,0.872)\end{array}$ & 0.001 & 0.215 & 0.129 & 0.110 \\
\hline & & Recessive & $\begin{array}{c}\text { GG vs } \\
\mathrm{AA}+\mathrm{GA}\end{array}$ & 3 & 35.0 & Fixed & $\begin{array}{c}0.701 \\
(0.564,0.872)\end{array}$ & 0.001 & 0.215 & 0.129 & 0.110 \\
\hline
\end{tabular}

$\mathrm{I}^{2}$, variation in OR attributable to heterogeneity; OR, odds ratio; 95\% CI, 95\% confidence interval; Random, random effects model; $p 1, \mathrm{p}$ value for OR; $p 2, \mathrm{p}$ value for heterogeneity; $p 3, p 4$ are $p_{\text {Egger }}$ and $p_{\text {Harbord }}$ for publication bias; Bold values are statistically significant $(p<0.05) ; \mathrm{Na}$, not available.

between rs2296651 polymorphisms of NTCP and HBV susceptibility is controversial. Yang et al [13] reported that the variant frequency of the rs2296651 A allele is decreased in HBV carriers, compared to that in HCs. But others have demonstrated that the GA genotype of rs2296651 promotes HBV infection ( $\mathrm{OR}=2.91, p=0.03$ for GA genotype) [11]. Subsequently, in large sample studies, rs2296651 mutants have been associated with resistance to $\mathrm{HBV}$ infection (OR of $\mathrm{GA}=0.36, p<0.001$ and $\mathrm{OR}$ of $\mathrm{AA}=0.16, p<0.001$, respectively) [10], (OR of $\mathrm{AA}=0.13$, $p<0.001$ ) [12]. In addition, no association of variants have been found at the SLC10A1 locus with susceptibility to persistent HBV infection among Southern Chinese [14].

In the current study, our data show that the proportion of the rs2296651-GA genotype was dramatically lower in CHB patients than in HCs, demonstrating a potential protective effect against HBV infection of the rs2296651-GA variant of NTCP. Our results are in line with the findings of Peng et al. [10] and Hu et al. [12], showing the low frequencies of rs2296651GA in CHB patients. Subsequently, a potential protective role of the rs2296651-GA mutation was further confirmed in our current study using meta-analysis, showing the NTCP rs2296651-GA genotype was inversely correlated with $\mathrm{HBV}$ infection $(\mathrm{OR}=0.593, p=0.028)$. Such data demonstrate that individuals with the rs2296651-GA genotype have significantly lower risk of HBV infection than those with the GG genotype.

There have been additional reports on the inverse correlations between the rs2296651 mutant and HBV susceptibility in regions with high minor allele frequency (MAF) [10,12], while no correlations have been observed in regions with low MAF $[13,14]$. These controversial findings might be due to different levels of genetic variations among the Asian population. Regarding the minor allele frequency of rs $2296651, \mathrm{MAF}$ is $7.5 \%$ in Chinese-Americans [29], 3.1-5\% in Koreans, $7.4 \%$ in Chinese and 9.2\% in Vietnamese [30]. Moreover, among the Chinese population there are different frequencies of the rs 2296651 mutant, i.e. $8.3 \%$ and $8.1 \%$ in Guangdong and Guangxi provinces (Southern China), $7.5 \%$ in Chongqing, 5.4\% in Hunan and Hubei provinces (Central China) and 2.4\% in Henan province (near Northern China) [13]. These reports are consistent with our current data, as well as other meta-analysis [10-13, 16]. However, there is no standard cutoff-value of MAF to accurately estimate HBV susceptibility at present, which needs to be further investigated.

Recently, it is reported that NTCP expression is decreased in HCC tumor tissue [31]. Kang et al. further demonstrate that the lower levels of NTCP expression in tumor tissues are associated with a poor postsurgery survival rate in HCC patients [9]. In addition, ectopic expression of NTCP in HCC inhibits tumor cell proliferation and growth [9]. However, the association between NTCP mutants and HCC is still controversial $[11,12]$. Our current study has shown that CHB patients with the rs2296651-GA genotype have a significantly decreased HCC risk, basing on meta-analysis of 3 studies (OR is $0.701, p=0.001$, in dominant model), consistent with results reported by $\mathrm{Hu}$ et al. [12].

The NTCP rs2296651-GA mutation, a nonsynonymous mutation in exon 4 causing an amino acid change, reduces $\mathrm{HBV}$ entrance into hepatocytes in 
vitro [28]. It might inhibit $\mathrm{HBV}$ viral replication and protect newly differentiated hepatocytes against HBV infection. Disabling this function of NTCP might wipe out the advantages in preventing HBV infection, persistent inflammatory injury and even hepatocarcinogenesis. In addition, NTCP is critical for maintaining homeostasis of bile acid [7, 32]. It had been reported that binding of HBV to NTCP alters bile acid metabolism [33] and that the rs2296651-GA mutant in NTCP is deleterious for the transport of bile acids [29]. The functional limitation of bile acid transportation and the metabolic disorder of bile acid might promote cell death of HBV infected hepatocytes, which would further prevent HBV replication and spread [33]. The metabolic disorder of bile acid and the low HBV replication level, which are likely caused by the rs2296651-GA mutant, might explain the lower occurrence of HCC and the lower HBV cccDNA level in HCC patients with down-regulated expression levels of NTCP [9]. It has been reported that the IL28B genotype is the strongest pretreatment predictor for sustained virologic response (SVR) in HCV genotype 1 patients based on Peg-IFN- $\alpha$ treatment, because IL-28B polymorphisms influences viral kinetics [34]. Moreover, IL-28B rs $12979860 \mathrm{C} / \mathrm{T}$ mutant is an important predictive factor in the development of $\mathrm{HCC}$ in liver cirrhosis patients [35]. Thus, our findings of NTCP polymorphisms among HBV patients, especially the results of the rs2296651-GA mutant, might also provide an insight for the interaction of $\mathrm{HBV}$ and host, and the development of HCC. Recently, in CHB patients with rs2296651-GA mutant (S267F variant), more virological response and sustained response with HBsAg loss at 24 weeks following Peg-IFN- $\alpha$ treatment were found [36]. The S267F variant on the NTCP gene was independently associated with sustained normalization of ALT following treatment with Peg-IFN- $\alpha$ in HBeAg-positive CHB patients [36], which provide additional support for the clinical significance of the rs2296651 beyond HBV entry. Understanding the underlying mechanism between NTCP polymorphisms and $\mathrm{HBV}$ infection/HBV related $\mathrm{HCC}$ would be helpful in designing a novel therapeutic agent/strategy for CHB.

Rs943277, located in intron 1 of chromosomes 14 in humans, was first genotyped in a Japanese population [37], but has had less research because the potential DNA-binding site for transcription factors was generally believed to be in the promoter region exon of SLC10A1 $[37,38]$. Recently, it has been reported that variants in the intron might also influence gene expression via regulating a transcription enhancer or silencer [39]. Moreover, neighboring variants of the promoter region might also lead to missense mutations which could reduce the uptake of bile acid and/or estrone sulfate by NTCP [29]. We undertook this study based on the assumption that rs 943277 is close to the promoter region of SLC10A1 [37]. Interestingly, our results of association analysis showed that the frequency of NTCP rs943277-GA genotype was higher in $\mathrm{CHB}$ patients than that in $\mathrm{HCs}$ (Adjusted $\mathrm{OR}=2.42, p=0.032$ ), as well as the frequency of $\mathrm{GA}+\mathrm{AA}$ (Adjusted $\mathrm{OR}=2.32, p=0.048$ ). The partial positive correlation demonstrated that rs943277-GA genotype was a potential hazardous variation in HBV susceptibility. It was speculated that the variation at rs943277 might promote HBV infection via influencing NTCP expression. Due to limited baseline research on NTCP, especially the rs943277-GA mutant, the function of the rs943277-GA mutant in influencing NTCP expression is still poorly understood [37, 40]. However, our data support an important clue for the functional study of the NTCP gene variation at rs943277. Further work will determine the exact role of the rs943277-GA mutant in the pathogenesis of HBV infection.

As for rs4646287, a functional genetic variant of NTCP is associated with HBV infection [13]. Despite the likelihood that the rs4646287 mutation might reduce the morbidity of HCC [13], there are controversial results for rs4646287 in HBV infection [13, 16, 18]. Our metaanalysis result $(\mathrm{OR}=0.962, p=0.492)$ supports the view that no firm genetic association has been established for rs4646287 with HBV infection [16]. For the development of HBV infection, it is reported that the rs7154439AA genotype might be associated with $\mathrm{HBV}$ clearance (adjusted $\mathrm{OR}=0.33,95 \% \mathrm{CI}=0.15-0.75, p=0.008$ in a codominant model) [18], but another study reports that the rs7154439 variants are not associated with the risk of HBV infection [19]. In our meta-analysis, rs7154439-AA mutants exhibited no significant difference in distribution between the HC group and CHB group. Similarly, the rs4646296-GC mutant showed no association with HBV infection, consistent with the sporadic data $[14,18]$ or meta-analysis $(\mathrm{OR}=1.017 . p=0.821$, codominant model). This disparity might be due to the relatively small sample sizes enrolled in the studies selected in this meta-analysis. As for rs17556915, rs9323529 and rs943276, there were very low minor allele frequency $(\mathrm{MAF})$ value $(<1.0 \%)$, and no association with HBV infection was found in present study. Considering the relatively small sample size for trial sequential analysis (TSA) or little in the literature, additional studies are needed to determine the correlation between rs4646287, rs7154439, rs464696, rs17556915, rs9323529 or rs943276 and HBV infection/ HCC occurrence in the future.

There were several limitations in the present study. Firstly, the selected hot spots might miss other important mutant sites. It would be better to sequence the whole NTCP gene to discover the role of new loci in the pathogenesis of CHB or HCC. Secondly, because of lower homozygosity for rs2296651 than expected in the CHB patients, the distribution of the minor allele was not consistent with the Hardy-Weinberg $(\mathrm{H}-\mathrm{W})$ equilibrium $(p<0.001)$ in our replication group. A similar HardyWeinberg disequilibrium also existed in other large cohorts $[10,12]$, which could explain the high heterogeneity in 
the present meta-analysis. Moreover, different genotyping methods and study designs might also contribute to the bias, which could also be the possible reasons for high heterogeneity of included studies in the metaanalysis. Thirdly, the frequencies of rs2296651-GA and rs943277-GA were relatively low in the population both in the patient group and healthy controls. Although metaanalysis has been introduced to confirm the conclusion, further comprehensive investigation using a large-scale multicenter population of varying ethnic origins, with different outcomes of infection, comparable durations of infection and therapeutic schedule, will be performed. Additionally, we were unable to assess the influence of NTCP expression by these mutants in liver tissues, due to limited acquisition of the liver biopsy specimens. However, in our future experiments we will determine the effect of rs943277-GA on the expression of SLC10A1.

In conclusion, the present study provided some polymorphism evidence for the perspective that NTCP gene variations correlate with $\mathrm{HBV}$ susceptibility and HBV-related HCC, basing on experimental study and meta-analysis. The most interesting of those variants,

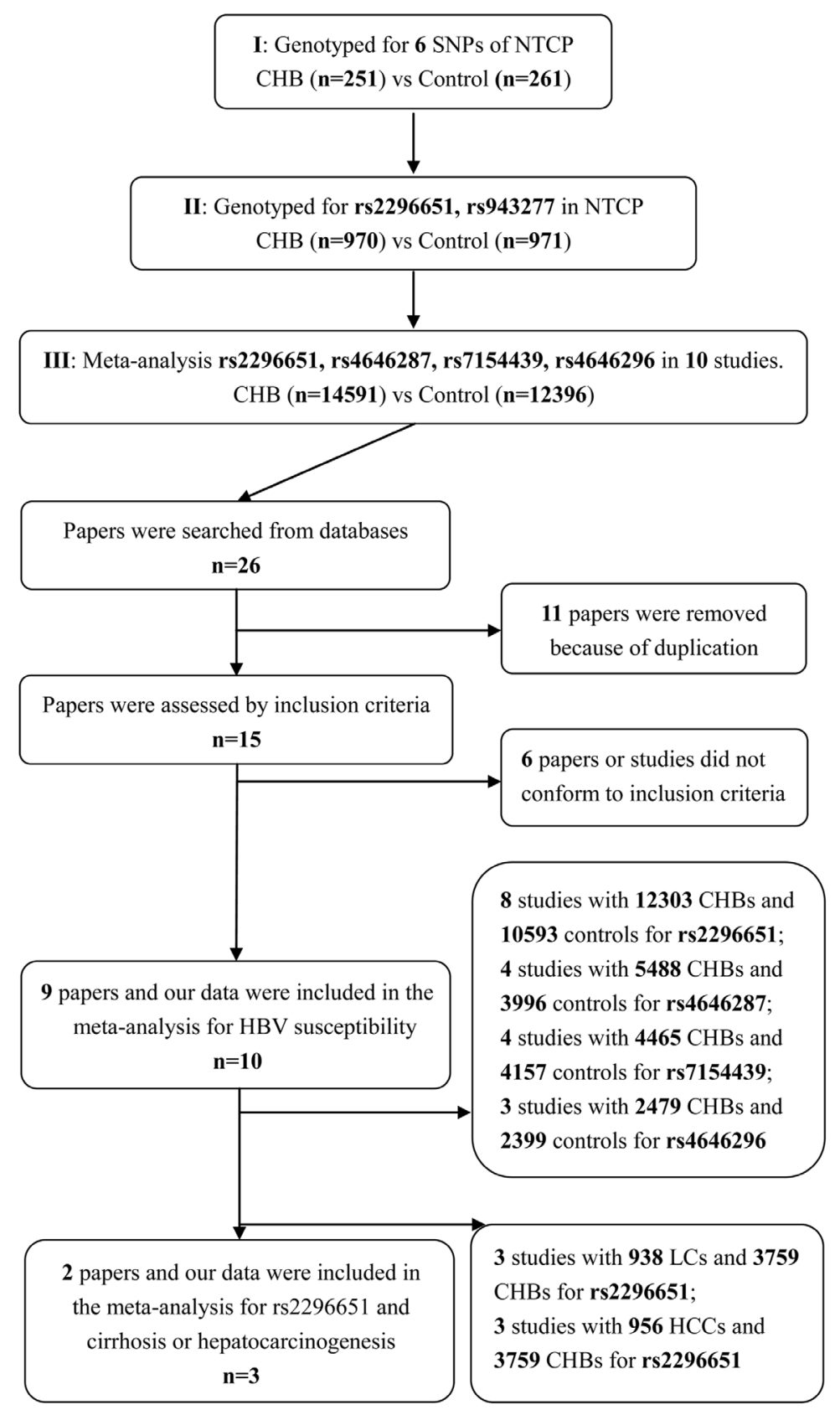

Figure 4: Grouping strategy for the population in the experimental study and selection for eligible studies included in this meta-analysis. 
rs2296651, might have a potential protective role in HBV susceptibility and hepatocarcinogenesis in regions with high MAF. The role of the partial positive association between rs943277 and HBV susceptibility will also be further investigated. These results might shed some light on the study of HBV infection and the occurrence of HBVrelated $\mathrm{HCC}$.

\section{MATERIALS AND METHODS}

\section{Subjects}

The study population included a discovery group and a replication group, with patients assigned according to the recruiting period. A total cohort of 1221 HBV patients in the Southeastern China region were recruited from Jun. 2011 to Dec. 2014 in the Department of Infectious Diseases, Ruijin Hospital, Shanghai Jiaotong University School of Medicine. 1232 ethnically and geographically matched healthy controls (HCs) undertaking a routine checkup were recruited from the Center of Health Examination of Ruijin Hospital in the same period. For the analysis, $251 \mathrm{HBV}$ outpatients who were investigated before Mar. 2012 were assigned as the discovery group of the study, and the HBV inpatients who were included in the study between June 2012 and Dec 2014 were regarded as the replication group to confirm the association. (Discovery group: Jun. 2011-Mar. 2012, CHB ( $\mathrm{n}=251)$ and HCs $(\mathrm{n}=261)$; Replication group: Aug. 2013-Dec. 2014, CHB ( $n=970)$ and HCs $(n=971)$ ).

The diagnosis of $\mathrm{CHB}$ was established by seropositivity of hepatitis B surface antigen (HBsAg) over a 6-month period according to the Chinese guideline of prevention and treatment for $C H B$ (2010 version) [41] and did not have any other type of liver diseases such as chronic hepatitis $\mathrm{C}$, hepatitis $\mathrm{D}$, hepatitis E, druginduced, autoimmune and alcoholic or nonalcoholic liver diseases. All participants were identified as Han Chinese. The demographic information included gender, age, birth-place, past and current residency. The clinic data were collected from clinical records and/or telephone interviews. The study is approved by the Ethics Committee of Ruijin Hospital, Shanghai Jiaotong University School of Medicine in accordance with the Helsinki Declaration. The characteristics of $\mathrm{CHB}, \mathrm{LC}, \mathrm{HCC}$ and $\mathrm{HC}$ are presented in Table1.

\section{Single nucleotide polymorphism (SNP) selection}

SNPs were selected using HapMap Data Rel 27 Phase II+III, Feb 2009, on NCBI B36 assembly, dbSNP b126 of Han Chinese Beijing (http://hapmap.ncbi.nlm. nih.gov/) and Haploview software 4.2 (Mark Daly's lab at Broad Institute, Cambridge, MA, USA). The criteria used for SNP selection were population-frequency and multiple, high-profile or inconsistent submitters. The core criterion was determined based on alteration of NTCP transcription, translation or function. Six SNPs (rs17556915, rs2296651 [10, 11, 28], rs464629 [18], rs9323529, rs943276 [37] and rs943277 [37]) were finally selected for evaluation. Meta-analysis was performed on rs2296651, rs4646287, rs7154439 and rs4646296. In the discovery group, all the six SNPs were genotyped. In the replication group, only rs2296651 and rs943277 were genotyped, according to the analysis result of discovery group.

\section{Genomic DNA extraction}

Genomic DNA was extracted from $5 \mathrm{ml}$ venous blood, using the DNA Extraction Kit (Tiangen Biotech Co., Ltd., Beijing, China) according to the manufacturer's instructions. After determination of genomic DNA concentration, the samples were stored at $-80^{\circ} \mathrm{C}$ until genetic polymorphism analyses.

\section{Genotyping}

Six SNPs (rs17556915, rs2296651, rs4646296, rs9323529, rs943276 and rs943277) were identified in the region of NTCP gene on chromosome 14 (range from 69310000 to 69335740 ). SNP ID numbers as well as sequence are available at http://www.ncbi.nlm.nih. gov/snp/ (Supplementary Table 1). The primers used for the corresponding SNPs polymerase chain reaction (PCR) amplification and SNaPshot extension reactions were designed, using Primer 5 software (Supplementary Table 1). SNPs were confirmed by multiplex SNaPshot technology, according to previously described [42], using an ABI fluorescence-based assay allelic discrimination method (Applied Biosystems, Bedford, MA).

PCR was performed as described previously [43, 44]. Briefly, in a total volume of $20 \mu$ lcontaining $1 \times$ ExTaq $0.2 \mu \mathrm{l}, 25 \mathrm{Mm} \mathrm{MgCl}_{2} 2 \mu \mathrm{l}, 25 \mathrm{mMdNTP}$ Mix $2 \mu \mathrm{l}$, (TaKaRa Bio, Dalian, China), $2 \mu$ genomic DNA, and 4 $\mu l$ of each primer. The PCR product was purified by $1 \mathrm{U}$ SAP (shrimp alkaline phosphatase) and 1 U Exonuclease I. The product was processed according to the ABI SNaPshot protocol. Extension was performed in a total volume of $10 \mu \mathrm{l}$ containing $5 \mu \mathrm{l}$ SNaPshot Multiplex Kit (ABI), $2 \mu 1$ PCR product, $1 \mu \mathrm{l}$ mixed extension primer and $2 \mu \mathrm{H}_{2} \mathrm{O}$. The samples were put through 28 cycles of denaturation at $96^{\circ} \mathrm{C}$, annealing at $50^{\circ} \mathrm{C}$, elongation a $60^{\circ} \mathrm{C}$, and a final extension at $72^{\circ} \mathrm{C}$. The extension product was purified by 1 U SAP. The SNP was confirmed using an ABI3130 genetic analyzer. Genotypes were determined automatically using Genemapper 4.0 software (Applied Biosystems).

\section{Meta-analysis on association of NTCP with HBV infection}

Pubmed, Embase, Web of Science and WanFang databases were used to search for SNPs related studies. 
Search words included sodium taurocholate cotransporting polypeptide or "NTCP" or "SLC10A1" or "S267F" or "rs2296651" or "rs4646287" or "rs7154439" or "rs17556915" or "rs4646296" or "rs9323529" or "rs943277" or "rs943276" and "hepatitis B" or "hepatitis B virus" or "HBV" or "HBV infection" or "CHB" or "liver cirrhosis" or "LC" or "Hepatocellular Carcinoma" or "HCC". Data were collected by three investigators (Peng Wang, Ruidong Mo and Xiaogang Xiang) (Figure 4).

The inclusion criteria were listed as follows: 1) Article focuses on an association between the polymorphism of NTCP or SLC10A1 and hepatitis B virus or HBV infection or CHB or LC or HCC; 2) Study design is a case-control study; 3) $\mathrm{CHB}$ diagnosis meets The Chinese Guideline of Prevention and Treatment for Chronic Hepatitis B (2010 version) [41] or The American Association for the Study of Liver Disease [45]; 4) Odds ratios with the $95 \%$ confidence interval $(95 \% \mathrm{CI})$ and allele frequencies are available. Using the Newcastle-Ottawa Scale (NOS), three criteria were applied to evaluate the quality of each study for meta-analysis, as described [46]: 4 stars for selection, 2 stars for comparability and 3 stars for exposure/outcome. Nine stars were regarded as the highest quality and more than six stars were deemed as a high quality study.

\section{Statistical analysis}

The significance was determined using student's $\mathrm{t}$ test or $\mathrm{Z}$ test in demographic and clinical data for two groups or continuous variables. The $\chi^{2}$ tests or the Fisher exact tests (two-sided) were used to compare the categorical variables. The differences between groups were examined using the respective genetics models of codominant, dominant, recessive and additive, as appropriate. Statistical significance was performed using the SPSS software version 17.0 (SPSS Inc., Chicago, IL, USA) and GraphPad Prism 5 (GraphPad Software Inc. CA, USA). Hardy-Weinberg disequilibrium, the odds ratios with a $95 \%$ confidence interval $(95 \% \mathrm{CI})$, logistic regression adjusted for age and gender were calculated by PLINK (v.1.07, http://pngu.mgh.harvard.edu/purcell/ plink/, 5 February 2015, date last accessed) [47].

Systematic review and meta-analysis were adopted to comprehensively evaluate the correlation of rs2296651 or rs4646287, rs7154439, rs4646296 and HBV susceptibility, and the association of rs2296651 and LC or HCC. The heterogeneity for the included articles was evaluated using Cochran's Q test and $\mathrm{I}^{2}$ statistics, which varied from 0 to $100 \%$. The heterogeneity was described as low (0-40\%), moderate (30-60\%), substantial (50$90 \%$ ), and considerable (75-100\%). Then, a fixed effect model or random effect model was applied, basing on the heterogeneity and Cochran's Q test. Additionally, Harbord's test or Egger's test or Begg's test was used to detect potential publication bias [48], using STATA (version 13.0, STATA Corp LP, College Station, Texas, USA). A two-sided $p$ value, $p<0.05$ was considered as statistically significant.

Larger sample size by integrating data of multiple different experiments could increase the power of metaanalysis, and may also increase random errors, which were the risks of reliability and significance of the metaanalysis. To evaluate whether there is enough power to reach firm conclusions and avoid misleading results from random errors, primary outcomes were analyzed by trial sequential analysis (TSA) [20] (TSA, version 0.9; Copenhagen Trial Unit, Copenhagen, Denmark, 2011). Prior to analysis, 5\% risk of a type I error, $90 \%$ of power, the O'Brien-Fleming function and relative risk reduction based on low bias were preset, according to the required information size in the TSA analysis. Sequential monitoring boundaries were utilized, including the required information size, the conventional significance boundaries $(Z= \pm 1.96)$, and the trial sequential monitoring boundaries (TSBM). A series of cumulative Z-curve are intercalated to evaluate the information and the required information size was further adjusted according to heterogeneity index score (HIS). The firm evidences of benefits and harmfulness were assumed if the Z-curve crossed the conventional boundaries and TSBM and the required HIS [49].

In addition, we also assessed the quality and robustness of the outcomes, using the methodology of Grading of Recommendations Assessment, Development, and Evaluation (GRADE) [50] (GRADEpro v3.6, the Cochrane Collaboration). According to a series of grading standards, it was determined whether the effect or association was specific. Large effect, plausible confounding would change the effect and dose-response gradient would be upgraded to some extent. Possible limitations in design, risk of bias, high heterogeneity or inconsistency, indirectness of evidence, imprecision of results, or high probability of publication bias would be downgraded. Randomized controlled trials are categorized as high quality, but non-RCT could be reduced. Finally, the importance of evidence was graded as high, moderate, low or very low grade and the quality of conclusion was classed as critical, important or low important for decision making. The importance and qualities of the conclusion in the present study are presented in Supplementary Figure 2.

\section{Author contributions}

Q.X. and X.G.X. conceived, designed and directed the overall project; W.C. and H.W directed partial experiments; P.W., G.D.Z., Y.M.X., H.J.Z. and L.Y.L. collected samples; R.T.L., Y.H.L., X.L.W. and Z.Q.L. collected data; P.W. and R.D.M. performed experiments and analyzed the data; P.W. and X.X.G. wrote the manuscript; Q.X., X.G.X. and S.S.B. reviewed the 
manuscript and approved final version. All authors had access to the study data and have reviewed and approved the final manuscript.

\section{CONFLICTS OF INTEREST}

The authors declare no competing financial interests.

\section{FUNDING}

This study was supported by the National Natural Science Foundation of China (No.81300316, No.81600463, No.81501733 and No.81570535). Shanghai Municipal Education Commission-Gaofeng Clinical Medicine Grant Support (20172008). The Natural Science Foundation of Shanghai (17ZR1417700). The Shanghai Three-Year Plan of the Key Subjects Construction in Public Health-Infectious Diseases and Pathogenic Microorganism (15GWZK0102). The Shanghai Three-Year Plan of the Clinical Skills and Innovations (16CR1002A). The National Clinical Key Specialty Construction Project of China (Infectious Diseases). The National Key Programs on Infectious Diseases of China (2017ZX10202202-005-004, 2017ZX10203201-008). Chenguang Program supported by Shanghai Education Development Foundation and Shanghai Municipal Education Commission (No. 15CG12).

\section{REFERENCES}

1. Trepo C, Chan HL, Lok A. Hepatitis B virus infection. Lancet. 2014; 384:2053-2063.

2. Liang X, Bi S, Yang W, Wang L, Cui G, Cui F, Zhang Y, Liu J, Gong X, Chen Y, Wang F, Zheng H, Wang F, et al. Epidemiological serosurvey of hepatitis $\mathrm{B}$ in China-declining HBV prevalence due to hepatitis B vaccination. Vaccine. 2009; 27:6550-6557.

3. Cui Y, Jia J. Update on epidemiology of hepatitis B and C in China. J Gastroenterol Hepatol. 2013; 28:7-10.

4. Beasley RP, Hwang LY, Lin CC, Chien CS. Hepatocellular carcinoma and hepatitis B virus. A prospective study of 22 707 men in Taiwan. Lancet. 1981; 2:1129-1133.

5. Lee MH, Yang HI, Liu J, Batrla-Utermann R, Jen CL, Iloeje UH, Lu SN, You SL, Wang LY, Chen CJ. Prediction models of long-term cirrhosis and hepatocellular carcinoma risk in chronic hepatitis B patients: risk scores integrating host and virus profiles. Hepatology. 2013; 58:546-554.

6. Yan H, Zhong G, Xu G, He W, Jing Z, Gao Z, Huang Y, Qi Y, Peng B, Wang H, Fu L, Song M, Chen P, et al. Sodium taurocholate cotransporting polypeptide is a functional receptor for human hepatitis B and D virus. eLife. 2012; 1:e00049.

7. Stieger B, Hagenbuch B, Landmann L, Hochli M, Schroeder A, Meier PJ. In situ localization of the hepatocytic $\mathrm{Na}+$ /
Taurocholate cotransporting polypeptide in rat liver. Gastroenterology. 1994; 107:1781-1787.

8. Tiollais P, Pourcel C, Dejean A. The hepatitis B virus. Nature. 1985; 317:489-495.

9. Kang J, Wang J, Cheng J, Cao Z, Chen R, Li H, Liu S, Chen X, Sui J, Lu F. Down-regulation of NTCP expression by cyclin D1 in hepatitis B virus-related hepatocellular carcinoma has clinical significance. Oncotarget. 2016; 8:56041-56050. https://doi.org/10.18632/oncotarget.10241.

10. Peng L, Zhao Q, Li Q, Li M, Li C, Xu T, Jing X, Zhu X, Wang Y, Li F, Liu R, Zhong C, Pan Q, et al. The p.Ser267Phe variant in SLC10A1 is associated with resistance to chronic hepatitis B. Hepatology. 2014; 61:1251-1260.

11. Li N, Zhang P, Yang C, Zhu Q, Li Z, Li F, Han Q, Wang Y, Lv Y, Wei P, Liu Z. Association of genetic variation of sodium taurocholate cotransporting polypeptide with chronic hepatitis B virus infection. Genet Test Mol Biomarkers. 2014; 18:425-429.

12. Hu HH, Liu J, Lin YL, Luo WS, Chu YJ, Chang CL, Jen CL, Lee MH, Lu SN, Wang LY, You SL, Yang HI, Chen CJ. The rs2296651 (S267F) variant on NTCP (SLC10A1) is inversely associated with chronic hepatitis $\mathrm{B}$ and progression to cirrhosis and hepatocellular carcinoma in patients with chronic hepatitis B. Gut. 2015.

13. Yang J, Yang Y, Xia M, Wang L, Zhou W, Jiang Y, Wang H, Qian J, Jin L, Wang X. A genetic variant of the NTCP gene is associated with HBV infection status in a Chinese population. BMC Cancer. 2016; 16:211.

14. Zhang Y, Li Y, Wu M, Cao P, Liu X, Ren Q, Zhai Y, Xie B, Hu Y, Hu Z, Bei J, Ping J, Liu X, et al. Comprehensive assessment showed no associations of variants at the SLC10A1 locus with susceptibility to persistent HBV infection among Southern Chinese. Sci Rep. 2017; 7:46490.

15. Stroffolini T, Esvan R, Biliotti E, Sagnelli E, Gaeta GB, Almasio PL. Gender differences in chronic HBsAg carriers in Italy: evidence for the independent role of male sex in severity of liver disease. J Med Virol. 2015; 87:1899-1903.

16. Su Z, Li Y, Liao Y, Cai B, Chen J, Zhang J, Li L, Ying B, Tao C, Zhao M, Ba Z, Zhang Z, Wang L. Polymorphisms in sodium taurocholate cotransporting polypeptide are not associated with hepatitis B virus clearance in Chinese Tibetans and Uygurs. Infect Genet Evol. 2016; 41:128-134.

17. Ezzikouri S, Chihab H, Elhabazi A, Wakrim L, Benjelloun S. Lack of Ser267Phe variant of sodium taurocholate cotransporting polypeptide among Moroccans regardless of hepatitis B virus infection status. BMC Infect Dis. 2017; 17:99.

18. Su Z, Li Y, Liao Y, Cai B, Chen J, Zhang J, Li L, Ying B, Tao C, Wang L. Association of the gene polymorphisms in sodium taurocholate cotransporting polypeptide with the outcomes of hepatitis B infection in Chinese Han population. Infect Genet Evol. 2014; 27:77-82. 
19. Chen X, Wang Y, Cheng K, Li J, Lou J, Ke J, Yang Y, Gong Y, Zhu Y, Wang L, Zhong R. Genetic variants in the regulatory region of SLC10A1 are not associated with the risk of hepatitis B virus infection and clearance. Infect Genet Evol. 2016; 44:495-500.

20. Brok J, Thorlund K, Wetterslev J, Gluud C. Apparently conclusive meta-analyses may be inconclusive--Trial sequential analysis adjustment of random error risk due to repetitive testing of accumulating data in apparently conclusive neonatal meta-analyses. Int J Epidemiol. 2009; 38:287-298.

21. Watashi K, Sluder A, Daito T, Matsunaga S, Ryo A, Nagamori S, Iwamoto M, Nakajima S, Tsukuda S, Borroto-Esoda K, Sugiyama M, Tanaka Y, Kanai Y, et al. Cyclosporin A and its analogs inhibit hepatitis B virus entry into cultured hepatocytes through targeting a membrane transporter, sodium taurocholate cotransporting polypeptide (NTCP). Hepatology. 2014; 59:1726-1737.

22. Nkongolo S, Ni Y, Lempp FA, Kaufman C, Lindner T, Esser-Nobis K, Lohmann V, Mier W, Mehrle S, Urban S. Cyclosporin A inhibits hepatitis $\mathrm{B}$ and hepatitis $\mathrm{D}$ virus entry by cyclophilin-independent interference with the NTCP receptor. J Hepatol. 2014; 60:723-731.

23. Drexler JF, Geipel A, Konig A, Corman VM, van Riel D, Leijten LM, Bremer CM, Rasche A, Cottontail VM, Maganga GD, Schlegel M, Muller MA, Adam A, et al. Bats carry pathogenic hepadnaviruses antigenically related to hepatitis B virus and capable of infecting human hepatocytes. Proc Natl Acad Sci U S A. 2013; 110:16151-16156.

24. Schieck A, Schulze A, Gahler C, Muller T, Haberkorn U, Alexandrov A, Urban S, Mier W. Hepatitis B virus hepatotropism is mediated by specific receptor recognition in the liver and not restricted to susceptible hosts. Hepatology. 2013; 58:43-53.

25. Meier A, Mehrle S, Weiss TS, Mier W, Urban S. Myristoylated PreS1-domain of the hepatitis B virus L-protein mediates specific binding to differentiated hepatocytes. Hepatology. 2013; 58:31-42.

26. Watashi K, Wakita T. Hepatitis B virus and hepatitis D virus entry, species specificity, and tissue tropism. Cold Spring Harb Perspect Med. 2015; 5:a021378.

27. Nguyen LH, Ko S, Wong SS, Tran PS, Trinh HN, Garcia RT, Ahmed A, Lutchman GA, Keeffe EB, Nguyen MH. Ethnic differences in viral dominance patterns in patients with hepatitis B virus and hepatitis $\mathrm{C}$ virus dual infection. Hepatology. 2011; 53:1839-1845.

28. Yan H, Peng B, Liu Y, Xu G, He W, Ren B, Jing Z, Sui J, Li W. Viral entry of hepatitis B and D viruses and bile salts transportation share common molecular determinants on sodium taurocholate cotransporting polypeptide. J Virol. 2014; 88:3273-3284.

29. Ho RH, Leake BF, Roberts RL, Lee W, Kim RB. Ethnicity-dependent polymorphism in $\mathrm{Na}+$-taurocholate cotransporting polypeptide (SLC10A1) reveals a domain critical for bile acid substrate recognition. J biol Chem. 2004; 279:7213-7222.

30. Pan W, Song IS, Shin HJ, Kim MH, Choi YL, Lim SJ, Kim WY, Lee SS, Shin JG. Genetic polymorphisms in Na+taurocholate co-transporting polypeptide (NTCP) and ileal apical sodium-dependent bile acid transporter (ASBT) and ethnic comparisons of functional variants of NTCP among Asian populations. Xenobiotica. 2011; 41:501-510.

31. Zollner G, Wagner M, Fickert P, Silbert D, Fuchsbichler A, Zatloukal K, Denk H, Trauner M. Hepatobiliary transporter expression in human hepatocellular carcinoma. Liver Int. $2005 ; 25: 367-379$.

32. Kullak-Ublick GA, Glasa J, Boker C, Oswald M, Grutzner U, Hagenbuch B, Stieger B, Meier PJ, Beuers U, Kramer W, Wess G, Paumgartner G. Chlorambucil-taurocholate is transported by bile acid carriers expressed in human hepatocellular carcinomas. Gastroenterology. 1997; 113:1295-1305.

33. Oehler N, Volz T, Bhadra OD, Kah J, Allweiss L, Giersch K, Bierwolf J, Riecken K, Pollok JM, Lohse AW, Fehse B, Petersen J, Urban S, et al. Binding of hepatitis B virus to its cellular receptor alters the expression profile of genes of bile acid metabolism. Hepatology. 2014; 60:1483-1493.

34. Thompson AJ, Muir AJ, Sulkowski MS, Ge D, Fellay J, Shianna KV, Urban T, Afdhal NH, Jacobson IM, Esteban R, Poordad F, Lawitz EJ, McCone J, et al. Interleukin-28B polymorphism improves viral kinetics and is the strongest pretreatment predictor of sustained virologic response in genotype 1 hepatitis C virus. Gastroenterology. 2010; 139:120-129.e118.

35. Fabris C, Falleti E, Cussigh A, Bitetto D, Fontanini E, Bignulin S, Cmet S, Fornasiere E, Fumolo E, Fangazio S, Cerutti A, Minisini R, Pirisi M, Toniutto P. IL-28B rs $12979860 \mathrm{C} / \mathrm{T}$ allele distribution in patients with liver cirrhosis: role in the course of chronic viral hepatitis and the development of HCC. J Hepatol. 2011; 54:716-722.

36. Thanapirom K, Suksawatamnuay S, Sukeepaisarnjaroen W, Treeprasertsuk S, Tanwandee T, Charatcharoenwitthaya P, Thongsawat S, Leerapun A, Piratvisuth T, Boonsirichan R, Bunchorntavakul C, Pattanasirigool C, Pornthisarn B, et al. Association of the S267F variant on NTCP gene and treatment response to pegylated interferon in patients with chronic hepatitis B: a multicentre study. Antivir Ther. 2017.

37. Saito S, Iida A, Sekine A, Ogawa C, Kawauchi S, Higuchi S, Nakamura Y. Catalog of 238 variations among six human genes encoding solute carriers (hSLCs) in the Japanese population. J Hum Genet. 2002; 47:576-584.

38. Shiao T, Iwahashi M, Fortune J, Quattrochi L, Bowman S, Wick M, Qadri I, Simon FR. Structural and functional characterization of liver cell-specific activity of the human sodium/taurocholate cotransporter. Genomics. 2000; 69:203-213.

39. Tokuhiro S, Yamada R, Chang X, Suzuki A, Kochi Y, Sawada T, Suzuki M, Nagasaki M, Ohtsuki M, Ono M, Furukawa H, Nagashima M, Yoshino S, et al. An intronic 
SNP in a RUNX1 binding site of SLC22A4, encoding an organic cation transporter, is associated with rheumatoid arthritis. Nat Genet. 2003; 35:341-348.

40. Al-Qahtani AA, Al-Anazi MR, Nazir N, Wani K, Abdo AA, Sanai FM, Khan MQ, Al-Ashgar HI, Albenmousa A, Al-Hamoudi WK, Alswat KA, Al-Ahdal MN. Association of single nucleotide polymorphisms in MicroRNAs with susceptibility to hepatitis B virus infection and HBV-related liver complications: a study in a Saudi Arabian population. J Viral Hepat. 2017.

41. Chinese Society of Hepatology and Chinese Society of Infectious Diseases, Chinese Medical Association. [The guideline of prevention and treatment for chronic hepatitis B (2010 version)]. [Article in Chinese]. Zhonghua Gan Zang Bing Za Zhi. 2011; 19:13-24.

42. Yan H, Yuan W, Velculescu VE, Vogelstein B, Kinzler KW. Allelic variation in human gene expression. Science. 2002; 297:1143.

43. Xiang X, Lu J, Dong Z, Zhou H, Tao W, Guo Q, Zhou X, Bao S, Xie Q, Zhong J. Viral sequence evolution in Chinese genotype $1 \mathrm{~b}$ chronic hepatitis $\mathrm{C}$ patients experiencing unsuccessful interferon treatment. Infect Genet Evol. 2011; 11:382-390.

44. Gohl DM, Vangay P, Garbe J, MacLean A, Hauge A, Becker A, Gould TJ, Clayton JB, Johnson TJ, Hunter R, Knights D,
Beckman KB. Systematic improvement of amplicon marker gene methods for increased accuracy in microbiome studies. Nat Biotechnol. 2016; 34:942-949.

45. Lok AS, McMahon BJ. Chronic hepatitis B. Hepatology. 2007; 45:507-539.

46. Stang A. Critical evaluation of the Newcastle-Ottawa scale for the assessment of the quality of nonrandomized studies in meta-analyses. Eur J Epidemiol. 2010; 25:603-605.

47. Purcell S, Neale B, Todd-Brown K, Thomas L, Ferreira MA, Bender D, Maller J, Sklar P, de Bakker PI, Daly MJ, Sham PC. PLINK: a tool set for whole-genome association and population-based linkage analyses. Am J Hum Genet. 2007; 81:559-575.

48. Harbord RM, Egger M, Sterne JA. A modified test for small-study effects in meta-analyses of controlled trials with binary endpoints. Stat Med. 2006; 25:3443-3457.

49. Wetterslev J, Thorlund K, Brok J, Gluud C. Trial sequential analysis may establish when firm evidence is reached in cumulative meta-analysis. J Clin Epidemioly. 2008; 61:64-75.

50. Guyatt GH, Oxman AD, Vist GE, Kunz R, Falck-Ytter Y, Alonso-Coello P, Schunemann HJ. GRADE: an emerging consensus on rating quality of evidence and strength of recommendations. BMJ. 2008; 336:924-926. 